TITLE:

\title{
Effects of the mutational combinations on the activity and stability of thermolysin.
}

\section{AUTHOR(S):}

Kusano, Masayuki; Yasukawa, Kiyoshi; Inouye, Kuniyo

\section{CITATION:}

Kusano, Masayuki ... [et al]. Effects of the mutational combinations on the activity and stability of thermolysin.. Journal of biotechnology 2010, 147(1): 7-16

\section{ISSUE DATE:}

2010-05-03

URL:

http://hdl.handle.net/2433/128776

\section{RIGHT:}

(c) 2010 Elsevier B.V.; この論文は出版社版でありません。引用の際には 出版社版をご確認ご利用ください。; This is not the published version. Please cite only the published version. 
Journal of Biotechnology

\section{Effects of the mutational combinations on the activity and stability of thermolysin}

Masayuki Kusano, Kiyoshi Yasukawa, Kuniyo Inouye*

Division of Food Science and Biotechnology, Graduate School of Agriculture, Kyoto University, Sakyo-ku, Kyoto 606-8502, Japan

Keywords: Activity-stability relationship; Mutational combination; Site-directed mutagenesis; Thermal stability; Thermolysin

Abbreviations: FAGLA, N-[3-(2-furyl)acryloyl]-glycyl-L-leucine amide; ZDFM, $N$-carbobenzoxy-L-aspartyl-L-phenylalanine methyl ester

*Corresponding author. Tel: +81-75-753-6266, Fax: +81-75-753-6265, E-mail address: inouye@kais.kyoto-u.ac.jp (K. Inouye) 


\section{Abstract}

We have previously indicated that three single mutations (Leu144 $\rightarrow$ Ser, Asp150 $\rightarrow$ Glu, and Ile168 $\rightarrow$ Ala) in the site-directed mutagenesis of thermolysin increase the activity and two single $\quad($ Ser53 $\rightarrow$ Asp and Leu155 $\rightarrow$ Ala $)$ and one triple $($ Gly8 $\rightarrow$ Cys/Asn60 $\rightarrow$ Cys/Ser65 $\rightarrow$ Pro) mutations increase the stability. In the present study, aiming to generate highly active and stable thermolysin variants, we combined these mutations and analyzed the effect of combinations on the activity and stability of thermolysin. The combination of the mutations of Leu144 $\rightarrow$ Ser and Asp150 $\rightarrow$ Glu yielded the most significant increase in the hydrolytic activities for $N$-[3-(2-furyl)acryloyl]-Gly-L-Leu amide (FAGLA) and $N$-carbobenzoxy-L-Asp-L-Phe methyl ester $($ ZDFM), while that of Leu144 $\rightarrow$ Ser and Ile168 $\rightarrow$ Ala abolished the activity. The combination of Ser53 $\rightarrow$ Asp and Leu155 $\rightarrow$ Ala yielded the greatest increase in the thermal stability, while that of Ser53 $\rightarrow$ Asp and Gly $8 \rightarrow$ Cys/Asn60 $\rightarrow$ Cys/Ser65 $\rightarrow$ Pro increased the stability as high as the individual mutations do. The combination of three mutations of Leu144 $\rightarrow$ Ser, Asp150 $\rightarrow$ Glu, and Ser53 $\rightarrow$ Asp yielded a remarkably activated and stabilized variant L144S/D150E/S53D. Its $k_{\text {cat }} / K_{\mathrm{m}}$ values in the hydrolysis of FAGLA and ZDFM were 8.6 and 10.2 times higher than those of wild-type thermolysin (WT), respectively, and its rate constant for thermal inactivation at $80^{\circ} \mathrm{C}$ was $60 \%$ of that of WT. 


\section{Introduction}

Thermolysin [EC 3.4.24.27] is a thermostable neutral metalloproteinase produced in the culture broth of Bacillus thermoproteolyticus (Endo, 1962; Inouye, 2003; Van den Burg and Eijsink, 2004). It requires one zinc ion for enzyme activity and four calcium ions for structural stability (Latt et al., 1969; Feder et al., 1971; Tajima et al., 1976), and catalyzes specifically the hydrolysis of peptide bonds containing hydrophobic amino acid residues (Morihara and Tsuzuki, 1970; Inouye et al., 1996). Thermolysin consists of a $\beta$-rich N-terminal domain and an $\alpha$-helical C-terminal domain (Holmes and Matthews, 1982; Hangauer et al., 1984). These two domains are connected by an $\alpha$-helix located at the bottom of the active site cleft. The activity and stability of thermolysin markedly increase with high concentration (1-5 M) of neutral salts (Inouye, 1992; Inouye et al., 1996, 1997, 1998a, 1998b; Oneda et al., 2004), although the mechanism of the activation and stabilization has not yet been well elucidated.

For various enzymes, site-directed mutagenesis and/or random mutations have been extensively performed, and mutations which confer the enzymes desirable properties, such as enhanced catalytic activity, improved (enhanced or reduced) thermal stability, enhanced tolerance against organic solvent, altered substrate specificity, or altered pH-dependence of activity, have been identified (Yutani et al., 1987; Shoichet et al., 1995; Lee et al., 2006a, 2006b; Arnorsdottir et al., 2007). If the effects of these mutations were additive, a variant enzyme with multiple mutations would have more desirable properties. However, it is generally known that mutations which increase enzyme activity accompany decrease in protein stability, and those which increase protein stability do decrease in enzyme activity (Shoichet et al., 1995; Lee et al., 2006a). 
In addition, it is not easy presently to predict the effect of mutational combination on enzyme properties (LiCata and Ackers, 1995; De Kreij et al., 2002; Mildvan, 2004).

Various mutations which alter enzyme properties have been identified for thermolysin (Mansfeld et al., 1997; Hanzawa and Kidokoro, 1999; Matsumiya et al., 2004, 2005; Kusano et al., 2006, 2009; Tatsumi et al., 2007; Yasukawa and Inouye, 2007; Takita et al., 2008). Of these mutations, activating mutations which increase the hydrolytic activity for $N$-[3-(2-furyl)acryloyl]-Gly-L-Leu amide (FAGLA) and $N$-carbobenzoxy-L-Asp-L-Phe methyl ester (ZDFM) and stabilizing mutations which increase the thermal stability are listed in Table 1 (In this study, the mutation of the residue for example Leu144 to Ser was designated as Leu144 $\rightarrow$ Ser, and the thermolysin variant bearing the mutation was designated as the thermolysin L144S variant or only L144S. The variant bearing multiple mutation for example Leu144 $\rightarrow$ Ser and Asp150 $\rightarrow$ Glu was designated as L144S/D150E). Mutation sites (Leu144, Asp 150, and Ile168) for the activating mutations and a site (Leu155) for one of the stabilizing mutations are located in the active site, while mutation sites (Gly8, Ser53, Asn60, and Ser65) for the other stabilizing mutations are in the N-terminal region (Fig. 1). It should be reminded that the Gly154-Leu155 bond is the autolysis site (Matsumiya et al., 2004, 2005). Regarding the effects of the mutational combinations on the activity and stability of thermolysin, we previously reported that the thermolysin variant G8C/N60C/S65P/L144S, which possessed the activating mutation Leu144 $\rightarrow$ Ser and the stabilizing mutation Gly8 $\rightarrow$ Cys/Asn60 $\rightarrow$ Cys/Ser65 $\rightarrow$ Pro, was more active and stable than wild-type thermolysin (WT) (Yasukawa and Inouye, 2007). However, the effects of other combinations have not yet been examined. The aim of this study is to generate highly active and stable thermolysin variants by combination of so far reported 
activating mutations and stabilizing mutations listed in Table 1 . The effects of the mutational combinations on the activity and stability of thermolysin are examined. It is demonstrated that the combination of Leu144 $\rightarrow$ Ser, Asp150 $\rightarrow$ Glu, and Ser53 $\rightarrow$ Asp yielded a thermolysin variant with much higher activity and stability than WT.

\section{Materials and methods}

\subsection{Materials}

Casein (Lot WKL1761) was purchased from Wako Pure Chemical (Osaka, Japan). FAGLA (Lot 111K1764) was from Sigma (St. Louis, MO). The concentration of FAGLA was determined spectrophotometrically using the molar absorption coefficient, $\varepsilon_{345}=766 \mathrm{M}^{-1} \mathrm{~cm}^{-1}$ (Feder, 1968; Inouye, 1992). ZDFM was prepared as described previously (Inouye, 1992), and its concentration was determined using the molar absorption coefficient, $\varepsilon_{257}=387 \mathrm{M}^{-1} \mathrm{~cm}^{-1}$ (Inouye, 1992). All other chemicals were of reagent grade and purchased from Nacalai Tesque (Kyoto, Japan). All spectrophotometric measurements were done with a Shimadzu UV-visible recording spectrophotometer UVmini-1240 (Kyoto, Japan).

\subsection{Expression and purification of thermolysin variants}

Expression and purification of thermolysin variants were performed as described previously (Yasukawa et al., 2007). In this expression system, the mature sequence of thermolysin containing the pelB leader sequence at its $\mathrm{N}$-terminus and the 
pre-prosequence of thermolysin were co-expressed. This system is not dependent on the autocatalytic activation of the thermolysin precursor containing pre-prosequence, but the mature form of thermolysin is produced with the aid of independently-produced pre-pro or pro sequences. This system might be suitable for our purpose of this paper because thermolysin variants could be produced in the culture supernatants even if they lost the autocatalytic digestion activity by the mutation (Yasukawa et al., 2007; Kusano et al., 2009). Briefly, pTMP1, an expression plasmid that co-expresses mature and pre-pro sequences of thermolysin as described above, was used. Site-directed mutagenesis was carried out with pTMP1 using a Quikchange ${ }^{\mathrm{TM}}$ site-directed mutagenesis kit (Stratagene, La Jolla, CA). E. coli K12 JM109 [recA1, endA1, gyrA96, thi, hsdR17, supE44, relA1, $\Delta\left(\right.$ lac-proAB), $F^{\prime}\left(\operatorname{traD} 36, \operatorname{proAB}^{+} l a c^{I q}\right.$, lacZAM15)] cells were transformed with each of the plasmids resulted. The transformants thus resulted were cultured, and the thermolysin variants were purified to homogeneity from the culture supernatants by column-chromatography.

\subsection{Sodium dodecyl sulfate-polyacrylamide gel electrophoresis (SDS-PAGE)}

SDS-PAGE was performed in a $12.5 \%$ polyacrylamide gel under reducing conditions according to the method of Laemmli (Laemmli, 1970). A constant current of $20 \mathrm{~mA}$ was applied for $80 \mathrm{~min}$. Samples were reduced by treatment with $2.5 \%$ 2-mercaptoethanol at $100^{\circ} \mathrm{C}$ for $10 \mathrm{~min}$. Proteins were stained with Coomassie Brilliant Blue R-250. The molecular-mass marker kit consisting of rabbit muscle phosphorylase $b(97.4 \mathrm{kDa})$, bovine serum albumin $(66.3 \mathrm{kDa})$, rabbit muscle aldolase $(42.4 \mathrm{kDa})$, bovine erythrocyte carbonic anhydrase $(30.0 \mathrm{kDa})$, soybean trypsin inhibitor $(20.1 \mathrm{kDa})$, 
and hen eggwhite lysozyme (14.4 kDa) was a product of Daiichi Pure Chemicals (Tokyo, Japan).

\subsection{Circular dichroism (CD)}

A Jasco J-720 (Tokyo, Japan) spectropolarimeter equipped with a Peltier system of cell temperature control was used for CD measurements. The system was routinely calibrated with an aqueous solution of recrystallized $d-10$ camphorsulphonic acid. Ellipticity is reported as mean residue molar ellipticity $[\theta]\left(\mathrm{deg} \cdot \mathrm{cm}^{2} \cdot \mathrm{dmol}^{-1}\right)$. The spectrometer conditions were typically: spectral range 195-260 nm, $100 \mathrm{mdeg}$ sensitivity; $0.1 \mathrm{~nm}$ resolutions; $4 \mathrm{~s}$ response time; $20 \mathrm{~nm} \mathrm{m^{-1 }}$ scan rate; and 7 accumulations. The control baseline was obtained with solvent and all the components without the proteins. $\mathrm{CD}$ spectra were recorded at $25^{\circ} \mathrm{C}$ using $1-\mathrm{mm}$ cell for the far-ultraviolet wavelength range. The concentration of the sample proteins was $0.3-2.0$ $\mu \mathrm{M}$ in $5 \mathrm{mM}$ Tris- $\mathrm{HCl}$ buffer $(\mathrm{pH} 7.5)$ containing $10 \mathrm{mM} \mathrm{CaCl} 2 . \mathrm{CD}$ spectra were processed with a Jasco software, and finally expressed in mean-residue molar ellipticity units.

\subsection{Hydrolysis of casein}

The casein-hydrolyzing activity of thermolysin was determined according to the methods described previously (Inouye, 2003; Kusano et al., 2009). The thermolysin solution $(0.5 \mathrm{ml})$ was added to $1.5 \mathrm{ml}$ of a solution containing $1.33 \%(\mathrm{w} / \mathrm{v})$ casein and $40 \mathrm{mM}$ Tris- $\mathrm{HCl}\left(\mathrm{pH} \mathrm{7.5)}\right.$, and incubated at $25^{\circ} \mathrm{C}$ for $30 \mathrm{~min}$. The reaction was stopped 
by adding $2 \mathrm{ml}$ of a solution containing $0.11 \mathrm{M}$ trichloroacetic acid, $0.22 \mathrm{M}$ sodium acetate, and $0.33 \mathrm{M}$ acetic acid. After $1-\mathrm{h}$ incubation at $25^{\circ} \mathrm{C}$, the reaction mixture was filtered through Whatman No. 2 filter paper ( $70 \mathrm{~mm}$ in diameter), and the absorbance $\left(A_{275}\right)$ at $275 \mathrm{~nm}$ was measured. One proteolytic unit (PU) of activity is defined as the amount of enzyme activity needed to liberate a quantity of acid soluble peptides corresponding to an increase in $A_{275}$ of $0.0074 \mathrm{~cm}^{-1} \mathrm{~min}^{-1}$ (equivalent to $1 \mu \mathrm{g}$ of tyrosine per min).

\subsection{Hydrolysis of FAGLA}

The thermolysin-catalyzed hydrolysis of FAGLA was measured by following the decrease in absorbance $\left(A_{345}\right)$ at $345 \mathrm{~nm}$ (Feder, 1968; Inouye, 1992; Inouye et al., 1996). The amount of FAGLA hydrolyzed was evaluated using the molar absorption difference due to hydrolysis, $\Delta \varepsilon_{345}=-310 \mathrm{M}^{-1} \mathrm{~cm}^{-1}$, at $25^{\circ} \mathrm{C}$ (Inouye, 1992). The reaction was carried out with thermolysin in $40 \mathrm{mM}$ HEPES-NaOH $(\mathrm{pH} 7.5)$ buffer containing $10 \mathrm{mM} \mathrm{CaCl}_{2}$ at $25^{\circ} \mathrm{C}$. The hydrolysis was carried out under pseudo-first order conditions, where the substrate concentration is much lower than the Michaelis constant $\left(K_{\mathrm{m}}\right)(>30 \mathrm{mM})$ (Inouye, 1992) because of the sparing solubility $(<6 \mathrm{mM})$ of FAGLA (Inouye, 1992; Inouye et al., 1996). Under the conditions, the kinetic parameters, $K_{\mathrm{m}}$ and the molecular activity $\left(k_{\mathrm{cat}}\right)$, cannot be determined separately, and the enzyme activity was evaluated by the specificity constant $\left(k_{\mathrm{cat}} / K_{\mathrm{m}}\right)$ throughout this study.

\subsection{Hydrolysis of ZDFM}


The thermolysin-catalyzed hydrolysis of ZDFM was measured by following the decrease in absorbance $\left(A_{224}\right)$ at $224 \mathrm{~nm}$ (Inouye, 1992). The amount of ZDFM hydrolyzed was evaluated using the molar absorption difference due to hydrolysis, $\Delta \varepsilon_{224}$ $=-493 \mathrm{M}^{-1} \mathrm{~cm}^{-1}$, at $25^{\circ} \mathrm{C}$ (Inouye, 1992). The reaction was carried out with thermolysin in $40 \mathrm{mM}$ Tris- $\mathrm{HCl}(\mathrm{pH} 7.5)$ buffer containing $10 \mathrm{mM} \mathrm{CaCl}_{2}$ at $25^{\circ} \mathrm{C}$. The kinetic parameters, $k_{\text {cat }}$ and $K_{\mathrm{m}}$, were determined with Kaleida Graph Version 3.5 (Synergy Software, Essex, VT), based on the Michaelis-Menten equation using the non-linear least-squares regression method (Sakoda and Hiromi, 1976).

\subsection{Thermal inactivation of thermolysin}

Thermolysin $(0.3-2.0 \mu \mathrm{M})$ in $40 \mathrm{mM}$ HEPES-NaOH (pH 7.5) buffer containing $10 \mathrm{mM} \mathrm{CaCl}_{2}$ was incubated at $80^{\circ} \mathrm{C}$ for a specified time. Then, it was incubated at $25^{\circ} \mathrm{C}$ for 1 min. The remaining activity of the thermolysin toward FAGLA hydrolysis was determined as described above. Assuming that the thermal inactivation of thermolysin is irreversible and consists of only one step (Yasukawa and Inouye, 2007; Takita et al., 2008; Kusano et al., 2009), the first-order rate constant, $k_{\mathrm{obs}}$, of the thermal inactivation was evaluated by plotting logarithm of the residual activity $\left(k_{\text {cat }} / K_{\mathrm{m}}\right)$ against the time of thermal treatment.

\section{Results}

3.1. Strategy for generating highly active and stable thermolysin variants by mutational 
combinations

We have already reported three activating mutations which increase the FAGLA- and ZDFM-hydrolyzing activities of thermolysin (Hanzawa and Kidokoro, 1999; Yasukawa and Inouye, 2007; Kusano et al., 2009) and three stabilizing mutations which increase its thermal stability (Mansfeld et al., 1997; Matsumiya et al., 2004, 2005; Yasukawa and Inouye, 2007; Takita et al., 2008), and they are listed in Table 1. In order to select variants with significantly increased activity and stability, we first designed four variants (L144S/D150E, L144S/I168A, D150E/I168A, and L144S/D150E/I168A) by combining the activating mutations and secondly another four variants (S53D/L155A, S53D/G8C/N60C/S65P, L155A/G8C/N60C/S65P, and S53D/L155A/G8C/N60C/S65P) by combining the stabilizing mutations. Six variants (L144S, D150E, I168A, S53D, L155A, and G8C/N60C/S65P) possessing individually the activating and stabilizing mutations were also examined as controls. All thermolysin variants were expressed and produced by the method developed by us (Yasukawa et al., 2007).

3.2. Characterization of fourteen thermolysin variants with the activating or stabilizing mutations using the culture supernatants of the E. coli transformants

E. coli cells were transformed with the expression plasmids for WT thermolysin and its fourteen variants with the activating or stabilizing mutations. Each transformant was cultured in a test tube, and the supernatant was harvested. Upon SDS-PAGE of the supernatant, the $34-\mathrm{kDa}$ protein band corresponding to mature 
thermolysin was detected for all 14 variants. The expression levels of most of the variants were comparable to that of the WT, but those of L144S/I168A and L144S/D150E/I168A were substantially reduced (Fig. 2A and B).

Table 2 shows the casein-hydrolysis activity of the culture supernatants produced by the transformants. The activity was detected for all variants except for two variants (L144S/I168A and L144S/D150E/I168A) obtained by combining activating mutations and three variants (L144S/D150E/L155A, L144S/D150E/S53D/L155A, and L144S/D150E/I168A/S53D/L155A/G8C/N60C/S65P) obtained by combining activating and stabilizing mutations, indicating that combining Leu144 $\rightarrow$ Ser with Ile $168 \rightarrow$ Ala lose the proteolytic activity of thermolysin. Loss of thermolysin activity by the combination Leu144 $\rightarrow$ Ser and Leu155 $\rightarrow$ Ala is described in the section of 3.6. Combination of the activating and stabilizing mutations.

3.3 Production and purification of twelve thermolysin variants with the activating or stabilizing mutations

For further characterization, WT and the twelve variants which had the casein-hydrolysis activity were expressed in E. coli and purified to homogeneity (Yasukawa et al., 2007). Starting from 350-650 $\mathrm{ml}$ of culture supernatants, the yields of the purified variants were in the range of $0.04-3.4 \mathrm{mg}$, which was almost comparable to that of WT (1.0 mg) as average. Upon SDS-PAGE, all purified variants exhibited a single band with a molecular mass of $34 \mathrm{kDa}$ (Fig. 2C). CD spectra of the purified variants at $195-260 \mathrm{~nm}$ were essentially the same as that of WT, suggesting that no significant conformational change was occurred in thermolysin by mutation (data not 
shown).

\subsection{Hydrolytic activities of twelve thermolysin variants for casein, FAGLA, and ZDFM}

Table 2 also shows the specific activity of thermolysin-catalyzed hydrolysis of casein at $\mathrm{pH} 7.5$ at $25^{\circ} \mathrm{C}$. The specific activities of the variants bearing the activating mutations were in the range of $30-100 \%$ of that of WT, and those of the variants bearing the stabilizing mutations were in the range of $60-110 \%$ of that of WT. It is indicated that the specific activities of the variants with mutations at Leu144 and Leu155 were reduced $(30 \%$ and $60-90 \%$ of that of WT, respectively) compared to those of the variants without these mutations (70-110\% of that of WT).

We have reported that thermolysin activity in the hydrolysis of FAGLA and ZDFM increases with increasing concentration of neutral salts such as $\mathrm{NaCl}$, and that the degree of $\mathrm{NaCl}$-induced activation, which is defined as the ratio of the $k_{\text {cat }} / K_{\mathrm{m}}$ value at $4 \mathrm{M} \mathrm{NaCl}$ to that at $0 \mathrm{M} \mathrm{NaCl}$, is in the range of 13-15 (Inouye, 1992; Inouye et al., 1997). Table 3 shows the $k_{\text {cat }} / K_{\mathrm{m}}$ values in the hydrolysis of FAGLA at 0 and $4 \mathrm{M} \mathrm{NaCl}$ and the degrees of the $\mathrm{NaCl}$-induced activation. The $k_{\text {cat }} / K_{\mathrm{m}}$ values at $0 \mathrm{M} \mathrm{NaCl}$ of the variants bearing the activating mutations were in the range of $210-700 \%$ of that of WT, while those of the variants bearing the stabilizing mutations were in the range of $80-120 \%$ of that of WT, indicating that thermolysin activity for FAGLA hydrolysis was much improved by introduction of the activating mutations. In contrast, the degrees of $\mathrm{NaCl}$-induced activation of the variants bearing the activating mutations were in the range of only $20-40 \%$ of that of WT, while those of the variants bearing the stabilizing mutations were in the range of $60-110 \%$ of that of WT. This indicates that the degree of 
the activation of $\mathrm{NaCl}$-induced activation is not much affected by the stabilizing mutations but is much suppressed by the activating mutations. Of all the variants bearing either the activating or stabilizing mutations, L144S/D150E showed the highest $k_{\text {cat }} / K_{\mathrm{m}}$ value at $0 \mathrm{M} \mathrm{NaCl}$, indicating that the mutations Leu144 $\rightarrow$ Ser and Asp $150 \rightarrow \mathrm{Glu}$ increase the FAGLA hydrolysis activity by 6.3 and 2.7 times, respectively, and their combination yields the most marked increase of 7.0 times.

Unlike FAGLA, ZDFM is a synthetic substrate to which the Michaelis-Menten kinetics is applicable to determine $k_{\text {cat }}$ and $K_{\mathrm{m}}$ separately (Inouye, 1992). All thermolysin variants examined showed the Michaelis-Menten type dependence of the initial reaction rate $\left(v_{0}\right)$ of the thermolysin-catalyzed hydrolysis of ZDFM on the substrate concentration at $\mathrm{pH} 7.5$ at $25^{\circ} \mathrm{C}$ (Fig. 3). The $k_{\text {cat }}$ and $K_{\mathrm{m}}$ values of WT and its variants were determined and are shown in Table 4 . The $k_{\text {cat }} / K_{\mathrm{m}}$ values of the variants bearing the activating mutations were in the range of $180-1,050 \%$ of that of WT, while those of the variants bearing the stabilizing mutations were in the range of $60-110 \%$ of that of WT. This indicates that the hydrolytic activity for ZDFM of thermolysin is significantly improved by the activating mutations, whereas it is not much affected by stabilizing mutations. The $k_{\text {cat }}$ and $K_{\mathrm{m}}$ values of the variants bearing the activating mutations were in the range of $30-80 \%$ and $130-290 \%$, respectively, indicating that the increase in their $k_{\text {cat }} / K_{\mathrm{m}}$ values can be ascribed solely to the increase in $k_{\text {cat }}$ induced by the mutations. Of all the variants bearing either the activating or stabilizing mutations, L144S/D150E had the highest $k_{\text {cat }} / K_{\mathrm{m}}$ value, indicating that the combination of the mutation of Leu144 $\rightarrow$ Ser giving 5.3-times increase and that of Asp150 $\rightarrow$ Glu giving 3.5-times increase yield the greatest increase of 10.5 times in the hydrolytic activity for ZDFM. This result is in good agreement with that observed for FAGLA (Table 3). 


\subsection{Thermal stability of twelve thermolysin variants}

The remaining FAGLA-hydrolysis activity of the thermolysin variants at $25^{\circ} \mathrm{C}$ after thermal treatment at $80^{\circ} \mathrm{C}$ was plotted against the thermal-treatment time (Fig. 4). The inactivation followed pseudo-first-order kinetics. The observed first-order rate constants, $k_{\mathrm{obs}}$, for the thermal inactivation are summarized in Table 5 . The $k_{\mathrm{obs}}$ values of the variants with the activating mutations were in the range of $90-180 \%$, while those of the variants with the stabilizing mutations were in the range of $10-30 \%$, indicating that the stability of thermolysin could be much improved by the stabilizing mutations. Of all the variants with either the activating or stabilizing mutations, S53D/L155A had the smallest $k_{\mathrm{obs}}$ value $(10 \%$ of that of WT), indicating that the combination of Ser53 $\rightarrow$ Asp and Leu155 $\rightarrow$ Ala yields the most significant increase in stability for thermal inactivation. The $k_{\mathrm{obs}}$ value of $\mathrm{L} 155 \mathrm{~A} / \mathrm{G} 8 \mathrm{C} / \mathrm{N} 60 \mathrm{C} / \mathrm{S} 65 \mathrm{P}$ was higher than that of S53D/L155A, but was smaller than those of L155A and G8C/N60C/S65P. On the other hand, the $k_{\mathrm{obs}}$ value of S53D/G8C/N60C/S65P was almost the same as those of S53D and $\mathrm{G} 8 \mathrm{C} / \mathrm{N} 60 \mathrm{C} / \mathrm{S} 65 \mathrm{P}$, indicating that the combination of Ser53 $\rightarrow$ Asp and Gly8 $\rightarrow$ Cys/Asn60 $\rightarrow$ Cys/Ser65 $\rightarrow$ Pro yields only as high increase in stability as the individual mutations.

\subsection{Combination of the activating and stabilizing mutations}

The results described above indicate that L144S/D150E and S53D/L155A exhibit the highest activity and stability, respectively, and that L144S/I168A lacks the 
activity (Table 2). Based on this evidence, we first prepared a variant L144S/D150E/S53D/L155A considering that it might have improved activity and stability, although it lacked catalytic activity (Table 2). Next L144S/D150E/S53D and L144S/D150E/L155A were prepared, and the former showed catalytic activity but the latter did not, indicating that the combination of the mutations of Leu144 $\rightarrow$ Ser and Leu155 $\rightarrow$ Ala, similarly to that of Leu144 $\rightarrow$ Ser and Ile168 $\rightarrow$ Ala, abolishes the catalytic activity (Table 2). As we expected, the variant L144S/D150E/I168A/S53D/L155A/G8C/N60C/S65P containing all of the activating and stabilizing mutations listed in Table 1 lacked catalytic activity (Table 2). It should be noted that the $34-\mathrm{kDa}$ protein band corresponding to mature thermolysin was detected in SDS-PAGE (Fig. 2B) of the supernatants of the E. coli transformants not only for L144S/D150E/S53D (lane 12) but also for the other three variants, L144S/D150E/L155A (lane 13), L144S/D150E/S53D/L155A (lane 14), and L144S/D150E/I168A/S53D/L155A/G8C/N60C/S65P (lane 15). This means that the mature thermolysin proteins for the latter three variants are produced from the transformants, although they lack the catalytic activity. Then, L144S/D150E/S53D was purified to homogeneity (lane 16 in Fig. 2C) and its casein- (Table 2), FAGLA- (Table 3), and ZDFM- (Fig. 3B and Table 4) hydrolysis activities and thermal stability (Fig. 4B and Table 5) were examined. The $k_{\text {cat }} / K_{\mathrm{m}}$ values in FAGLA and ZDFM hydrolysis were 8.6 and 10.2-fold higher than those of WT, respectively, and the rate constant $\left(k_{\mathrm{obs}}\right)$ for thermal inactivation at $80^{\circ} \mathrm{C}$ was $60 \%$ of that of WT, indicating that L144S/D150E/S53D was much improved in both activity and stability. It is interesting to note that both activity and stability are enhanced in L144S/D150E/S53D. 


\section{Discussion}

4.1. Increase and decrease in thermolysin activity by the combinations of the mutations selected from the activating mutations, Leu144 $\rightarrow$ Ser, Asp150 $\rightarrow$ Glu, and Ile $168 \rightarrow$ Ala

Of the four thermolysin variants multiply bearing activating mutations, two (L144S/D150E and D150E/I168A) showed improved hydrolytic activity both for FAGLA and ZDFM, while the other two (L144S/I168A and L144S/D150E/I168A) had no detectable activity. This suggests that the mutation Asp $150 \rightarrow$ Glu could be effective in increasing the activity by combining with another activating mutation, while Leu144 $\rightarrow$ Ser and Ile168 $\rightarrow$ Ala are liable to abolish the activity when they are combined.

Asp150 is located at the C-terminal loop-1 (Asp150-Gly162) in the active site. All four variants bearing the mutation Asp150 $\rightarrow$ Glu (D150E, L144S/D150E, D150E/I168A, and S53D/L144S/D150E) showed the following features in ZDFM hydrolysis: Their $K_{\mathrm{m}}$ values are smaller than that of WT, being in the range of 30 to $80 \%$ of that of WT; and their $k_{\text {cat }}$ values are higher than that of WT, being in the range of 260 to $290 \%$ of that of WT (Table 4). This suggests that the replacement of Asp150 with Glu stabilizes both enzyme-substrate complex and transition state. This feature has not been anticipated by the structural data (Yutani et al., 1987; Shoichet et al., 1995), in which no residues in the C-terminal loop 1 are involved in the binding with the substrate. Comparing the effect of the mutation Asp $150 \rightarrow$ Glu on the $k_{\text {cat }} / K_{\mathrm{m}}$ values in the FAGLA hydrolysis (Table 3), the same tendency (L144S/D150E > D150E/I168A > D150E) was observed with that in the ZDFM hydrolysis (Table 4), suggesting that the effect of the 
mutation on the catalytic mechanism might be the same for both substrates. We speculate that there might be any interaction of Asp150 with substrate during catalysis probably by conformational change. It has been previously reported that Asp $150 \rightarrow$ Lys and Asp150 $\rightarrow$ Arg abolish and Asp150 $\rightarrow$ His reduces catalytic activity (Kusano et al., 2009), suggesting that positive charge at the position 150 of thermolysin might be unfavorable for catalysis.

Leu144 and Ile168 are located in the $\alpha$-helices 1 (Val139-Thr149) and 2 (Ala163-Val176) in the active site, respectively. Their side chains are buried in the interior of the protein. Therefore, Leu144 $\rightarrow$ Ser and Ile168 $\rightarrow$ Ala are thought to increase the flexibility of the enzyme by decreasing the density of the inner part of thermolysin (Hanzawa and Kidokoro, 1999; Yasukawa and Inouye, 2007; Kusano et al., 2009). The increase in the catalytic activity observed with L144S and I168A (Tables 3 and 4) might be ascribed to the increase in the flexibility. On the other hand, L144S/I168A lacks catalytic activity (Table 2). This suggests that the active-site mutations Leu144 $\rightarrow$ Ser and Ile168 $\rightarrow$ Ala are liable to lose catalytic activity by the combination with each other. Consequently, we have an idea that in the combination of the active-site mutations for activity improvement, mutations at the active-site $\alpha$-helix, like Leu144 $\rightarrow$ Ser and Ile $168 \rightarrow$ Ala, are less suitable than those at the active-site loop, like Asp150 $\rightarrow$ Glu.

4.2. Increase in the stability of thermolysin by combining the mutations selected from the stabilizing mutations, Ser53 $\rightarrow$ Asp, Leu155 $\rightarrow$ Ala, and Gly8 $\rightarrow$ Cys $/$ Asn60 $\rightarrow$ Cys $/$ Ser65 $\rightarrow$ Pro

All seven thermolysin variants bearing the stabilizing mutations had improved 
stability in the order of S53D/L155A > S53D/L155A/G8C/N60C/S65P, L155A/G8C/N60C/S65P > S53D, L155A, G8C/N60C/S65P, S53D/G8C/N60C/S65P (Table 5). This suggests that the mutations of Ser53 $\rightarrow$ Asp and Leu155 $\rightarrow$ Ala and those of Leu155 $\rightarrow$ Ala and Gly8 $\rightarrow$ Cys/Asn60 $\rightarrow$ Cys/Ser65 $\rightarrow$ Pro might be additive while the mutations Ser53 $\rightarrow$ Asp and Gly8 $\rightarrow$ Cys/Asn60 $\rightarrow$ Cys/Ser65 $\rightarrow$ Pro are non-additive

It has been thought that the stabilization of thermoylsin by Ser53 $\rightarrow$ Asp may be due to the electrostatic interaction between Lys45 and the Asp residue introduced at the position 53 (Takita et al., 2008), and that by Gly8 $\rightarrow$ Cys/Asn60 $\rightarrow$ Cys/Ser65 $\rightarrow$ Pro is due to the introduction of a disulfide bridge between the positions 8 and 60 (Mansfeld et al., 1997; Yasukawa and Inouye, 2007). High $\mathrm{CaCl}_{2}$ concentration (100 mM) enhances the thermal stability of WT to almost the same level as that of the thermolysin variant S53D (Takita et al., 2008). It also enhances the stability of the wild-type thermolysin-like protease from B. stearothermophilus (TLP-ste) [EC 3.4.24.4] toward guanidine hydrochloride to almost the same level as that of the variant TLP-ste G8C/N60C/S65P (Durrschmidt et al., 2005). These two findings suggested that $\mathrm{Ca}^{2+}$ ion, which is considered bound at the $\mathrm{Ca}^{2+}$-binding site III (the $\mathrm{Ca}^{2+}$ ion bound at this site is designated Ca3) located in the proximity of the surface loop (residues 55-69) in the $\mathrm{N}$-terminal region, plays an important role in stability. We speculate that both mutations make thermolysin hold $\mathrm{Ca} 3$ tightly. The role of $\mathrm{Ca}^{2+}$ ion-containing surface loop on enzyme stability have been pointed out in various enzymes such as subtilisin (Davail et al., 1994), 3-isopropylmalate dehydrogenase (Wallon et al., 1997), citrate synthase (Gerike et al., 1997), and $\alpha$-amylase (Lee et al., 2006a, 2006b; Aghajari et al., 1998), suggesting that the stabilization of $\mathrm{Ca}^{2+}$ ion in a surface loop is one of the effective strategies for stabilization of enzyme. 
The stabilizing mechanism by Leu155 $\rightarrow$ Ala was first thought to suppress the autolysis observed at the peptide bond between Gly154-Leu155 (Matsumiya et al., 2004, 2005). However, the observed first-order rate constant for the thermal inactivation at $80^{\circ} \mathrm{C}$ of L155A is $30 \%$ of that of WT (Table 5). This value is similar to those of the 7 active-site variants (F114H, D150H, D150W, I168H, S169A, N227A, and S234A) being in the range of $30-70 \%$ of that WT (Kusano et al., 2009). In addition, the specific activity in casein hydrolysis of L155A is $60 \%$ of that of WT (Table 2), and is similar to those of the 7 variants, the specific activity of which are in the range of $30-80 \%$ of that of WT (Kusano et al., 2009). The stabilization by Leu155 $\rightarrow$ Ala could be due to suppressing the autolysis. However, in addition to this, there is a possibility that this mutation could increase the stability in a similar way to that of the other 7 variants. There are three $\mathrm{Ca}^{2+}$-binding sites (I, II, and IV) in the C-terminal region. Regarding this issue, the effect of the mutations on the stabilization of the $\mathrm{Ca}^{2+}$-binding sites should be examined in the next subject.

4.3. Correlation between the degree of the salt-induced activation and activity of the thermolysin variants in the hydrolysis of FAGLA

The remarkable activation of thermolysin by high concentration of salt has been examined from two aspects, namely, the decrease in the dielectric constant of the reaction medium by high concentration of salt and the interaction between ions of salt and charges on the surface of the enzyme (Inouye, 1992; Inouye et al., 1996, 1997, 1998a, 1998b; Oneda et al., 2004). Weak and negative correlation $(\gamma=-0.54)$ has been observed between the activity and the degree of activation at $4 \mathrm{M} \mathrm{NaCl}$ in the hydrolysis 
of FAGLA with WT and the 12 single active-site variants (Kusano et al., 2009). In the present study, relatively strong and negative correlation $(\gamma=-0.79)$ has been observed between the activity and the degree of the activation with WT and the 13 variants (Fig. 5A). Interestingly, all variants with the improved activity shows the reduced degree of the activation (in the range of 3 to 5), raising a possibility that the salt-induced activation might be replaced by the mutational activation.

\subsection{Correlation between the activity and stability of the thermolysin variants}

We examined whether the results obtained in this study was corresponding to an idea that the catalytic performance of the enzyme is a compromise between its activity and stability. Comparing the FAGLA-hydrolysis activity and the first-order rate constant $\left(k_{\text {obs }}\right)$ for the thermal inactivation at $80^{\circ} \mathrm{C}$ of WT and all 13 variants, weak correlation $(\gamma=0.51)$ is observed (Fig. 5B). Interestingly, the correlation for 10 variants except for L144S, L144S/D150E, and L144S/D150E/S53D, increases considerably $(\gamma=$ 0.86 ), indicating that the activation by Leu144 $\rightarrow$ Ser is not much accompanied with decrease in stability compared to Asp $150 \rightarrow$ Glu and Ile168 $\rightarrow$ Ala. Totally, the mutations which increase activity are accompanied with decrease in stability.

4.5. Increase in the activity and stability of thermolysin by the combinations of mutations selected from Leu144 $\rightarrow$ Ser, Asp 150 $\rightarrow$ Glu, and Ser53 $\rightarrow$ Asp

A variant, L144S/D150E/S53D, bearing both activating and stabilizing mutations has higher activity and stability than WT. Its $k_{\text {cat }} / K_{\mathrm{m}}$ values in the hydrolysis 
of FAGLA and ZDFM are almost the same as those of L144S/D150E, respectively (Tables 3 and 4). However, its $k_{\mathrm{obs}}$ value is 2 to 3 -fold higher than those of the 7 variants bearing the three stabilizing mutations (Table 5), which is opposite to our previous result that the mutation Leu144 $\rightarrow$ Ser does not affect the stability enhanced by the triple mutation Gly8 $\rightarrow$ Cys/Asn60 $\rightarrow$ Cys/Ser65 $\rightarrow$ Pro (Yasukawa and Inouye, 2007). The $k_{\text {obs }}$ values of L144S, D150E, and L144S/D150E are almost the same as that of WT, and those of S53D and L144S/D150E/S53D are 20\% and 60\% of that of WT. By combining the double mutation Leu144 $\rightarrow$ Ser/Asp150 $\rightarrow$ Glu with the mutation Ser53 $\rightarrow$ Asp, the stabilization gained by Ser53 $\rightarrow$ Asp is attenuated by a considerable extent, although the reason of the destabilizing effect of the combination of the activating mutations Leu144 $\rightarrow$ Ser and Asp150 $\rightarrow$ Glu on the stabilized S53D variant is not clear. Similar results, however, have been reported in other enzymes: In the case of Pseudomonas fluorescens p-hydroxybenzoate hydroxylase, the combination of the activating mutation Cys $211 \rightarrow$ Ile and the stabilizing mutation Met52 $\rightarrow$ Val generated a highly active and stable variant M52V/Cys211I, although its stability was lower than that of M52V (Suemori and Iwakura, 2007), and in the case of Trametes multicolor pyranose 2-oxidase, the combination of the activating mutation Leu537 $\rightarrow$ Gly and the stabilizing mutation Glu542 $\rightarrow$ Lys or Arg generated highly active and stable variants, L537G/E542K and L537G/E542R, although their respective stabilities were lower than those of E542K and M542R (Spadiut et al., 2009).

In conclusion, a highly active and stable thermolysin variant (L144S/D150E/S53D) was generated by the combination of the two activating mutations Leu144 $\rightarrow$ Ser and Asp150 $\rightarrow$ Glu and one stabilizing mutation Ser53 $\rightarrow$ Asp. This variant and others presented as well in this study might be useful not only for 
elucidating the structure-function relationship of thermolysin but also for food science and technology in degradation and engineering of food proteins (Asaoka et al., 2009) and synthesis of bioactive peptides such as aspartame or L-aspartyl-L-phenylalanine methylester (Inouye, 1992, 2003). It is worthy to note that the L144S/D150E/S53D variant could be a suitable tool for studying the relationship between activity and stability of protein.

\section{Acknowledgments}

This study was supported in part by Grants-in-Aid for Scientific Research (Nos. 17380065 and 20380061 to K. I.) and for JSPS Fellows (No. 19-7098 to M. K.) from the Japan Society for the Promotion of Science. 


\section{References}

Aghajari, N., Feller, G., Gerday, C., Haser, R., 1998. Crystal structure of the psychrophilic $\alpha$-amylase from Alteromonas haloplanctis in its native form and complexed with an inhibitor. Protein Sci. 7, 564-572.

Arnorsdottir, J., Helgadottir, S., Thorbjarnardottir, S.H., Eggertsson, G., Kristjansson, M.M., 2007. Effect of selected Ser/Ala and Xaa/Pro mutations on the stability and catalytic property of a cold adapted subtilisin-like serine protienase. Biochim. Biophys. Acta 1774, 749-755.

Asaoka, K., Yasukawa, K., Inouye, K., 2009. Coagulation of soyproteins induced by thermolysin and comparison of the coagulation reaction with that induced by subtilisin Carlsberg. Enzyme Microbial Technol. 44, 229-234.

Davail, S., Feller, G., Narinx, E., Gerday, C., 1994. Cold adaptation of proteins. Purification, characterization, and sequence of the heat-labile subtilisin from the Antarctic psychrophile Bacillus TA41. J. Biol. Chem. 269, 17448-17453.

De Kreij, A., Van den Burg, B., Venema, G., Vriend, G., Eijsink, V.G., Nielsen, J.E., 2002. The effects of modifying the surface charge on the catalytic activity of a thermolysin-like protease. J. Biol. Chem. 277, 15432-15438.

Durrschmidt, P., Mansfeld, J., Ulbrich-Hofmann, R., 2005. An engineered disulfide bridge mimics the effect of calcium to protect neutral protease against local unfolding. FEBS J. 272, 1523-1534.

Endo, S., 1962. Studies on protease produced by thermophilic bacteria. J. Ferment. Technol. 40, 346-353.

Feder, J., 1968. A spectrophotometric assay for neutral protease. Biochem. Biophys. 
Res. Commun. 32, 326-332.

Feder, J., Garrett, L.R., Wildi, B.S., 1971. Studies on the role of calcium in thermolysin. Biochemistry 10, 4552-4556.

Gerike, U., Danson, M.J., Russel, N.J., Hough, D.W., 1997. Sequencing and expression of the gene encoding a cold-adaptive citrate synthase from Antarctic bacterium, strain DS2 3R. Eur. J. Biochem. 248, 49-57.

Hangauer, D.G., Monzingo, A.F., Matthews, B.W., 1984. An interactive computer graphics study of thermolysin-catalyzed peptide cleavage and inhibition by $N$-carboxymethyl dipeptides. Biochemistry 23, 5730-5741.

Hanzawa, S. Kidokoro, S., 1999. Thermolysin. In: Flickinger, M.C., Drew, S.W. (Eds.), Encyclopedia of Bioprocess Technology: Fermentation, Biocatalysis, and Bioseparation. John Wiley \& Sons, New York, pp. 2527-2535.

Holmes, M.A., Matthews, B.W., 1982. Structure of thermolysin refined at $1.6 \AA$ resolution. J. Mol. Biol. 160, 623-639.

Inouye, K., 1992. Effects of salts on thermolysin: activation of hydrolysis and synthesis of $N$-carbobenzoxy-L-aspartyl-L-phenylalanine methyl ester, and a unique change in the absorption spectrum of thermolysin. J. Biochem. 112, 335-340.

Inouye, K., 2003. Thermolysin. In: Whitaker, J.R., Voragen, A.G.J., Wong, D.W.S. (Eds.), Handbook of Food Enzymology. Marcel Dekker, New York, pp. 1019-1028. Inouye, K., Kuzuya, K., Tonomura, B., 1998a. Effect of salts on the solubility of thermolysin: a remarkable increase in the solubility as well as the activity by the addition of salts without aggregation or dispersion of thermolysin. J. Biochem. 123, 847-852.

Inouye, K., Kuzuya, K., Tonomura, B., 1998b. Sodium chloride enhances markedly the 
thermal stability of thermolysin as well as its catalytic activity. Biochim. Biophys. Acta $1388,209-214$

Inouye, K., Lee, S.-B., Tonomura, B., 1996. Effect of amino acid residues at the cleavable site of substrates on the remarkable activation of thermolysin by salts. Biochem. J. 315, 133-138.

Inouye, K., Lee, S.-B., Nambu, K., Tonomura, B., 1997. Effects of pH, temperature, and alcohols on remarkable activation of thermolysin by salts. J. Biochem. 122, 358-364.

Kusano, M., Yasukawa, K., Hashida, Y., Inouye, K., 2006. Engineering of the $\mathrm{pH}$-dependence of thermolysin activity as examined by site-directed mutagenesis of Asn112 located at the active site of thermolysin. J. Biochem. 139, 1017-1023.

Kusano, M., Yasukawa, K., Inouye, K., 2009. Insights into the catalytic roles the polypeptide regions in the active site of thermolysin and generation of the thermolysin variants with high activity and stability. J. Biochem. 145, 103-113.

Laemmli, U.K., 1970. Cleavage of structural proteins during the assembly of the head of bacteriophage T4. Nature 227, 680-685.

Latt, S.A., Holmquist, B., Vallee, B.L., 1969. Thermolysin: a zinc metalloenzyme. Biochem. Biophys. Res. Commun. 37, 333-339.

Lee, S., Mouri, Y., Minoda, M., Oneda, H., Inouye, K., 2006a. Comparison of the wild-type $\alpha$-amylase and its variant enzymes in Bacillus amyloliquefaciens in activity and thermal stability, and insights into engineering the thermal stability of Bacillus $\alpha$-amylase. J. Biochem. 139, 1007-1015.

Lee, S., Oneda, H., Minoda, M., Tanaka, A., Inouye, K., 2006b. Comparison of starch hydrolysis activity and thermal stability of two Bacillus licheniformis $\alpha$-amylase and insights into engineering $\alpha$-amylase variants active under acidic conditions. J. Biochem. 
139, 997-1005.

LiCata, V.J., Ackers, G.K., 1995. Long-range, small magnitude nonadditivity of mutational effects in proteins. Biochemistry $34,3133-3139$.

Mansfeld, J., Vriend, G., Dijkstra, B.W., Veltman, O.R., Van den Burg, B., Venema, G., Ulbrich-Hofmann, R., Eijsink, V.G., 1997. Extreme stabilization of a thermolysin-like protease by an engineered disulfide bond. J. Biol. Chem. 272, 11152-11156.

Matsumiya, Y., Nishikawa, K., Aoshima, H., Inouye, K., Kubo, M., 2004. Analysis of autodegradation sites of thermolysin and enhancement of its thermostability by modifying Leu155 at an autodegradation site. J. Biochem. 135, 547-553.

Matsumiya, Y., Nishikawa, K., Inouye, K., Kubo, M., 2005. Mutational effect for stability in a conserved region of thermolysin. Lett. Appl. Microbiol. 40, 329-334.

Mildvan, A.S., 2004. Inverse thinking about double mutants of enzymes. Biochemistry 43, 14517-14520.

Morihara, K., Tsuzuki, H., 1970. Thermolysin: kinetic study with oligopeptides. Eur. J. Biochem. 15, 374-380.

Oneda, H., Muta, Y., Inouye, K., 2004. Substrate-dependent activation of thermolysin by salt. Biosci. Biotechnol. Biochem. 68, 1811-1813.

Sakoda, M., Hiromi, K., 1976. Determination of the best-fit values of kinetic parameters of the Michaelis-Menten equation by the method of least squares with Taylor expansion. J. Biochem. 80, 547-555.

Shoichet, B.K., Baase, W.A., Kuroki, R., Matthews, B.W., 1995. A relationship between protein stability and protein function. Proc. Natl. Acad. Sci. USA 92, 452-456. Spadiut, O., Leitner, C., Salaheddin, C., Varga, B., Vertessy, B.G., Tan, T.-C., Divne, C., Haltrich, D., 2009. Improving thermostability and catalytic activity of pyranose 
2-oxidase from Trametes multicolor by rational and semi-rational design. FEBS J. 276, 776-792.

Suemori, A., Iwakura, M., 2007. A systematic and comprehensive combinatorial approach to simultaneously improve the activity, reaction specificity, and thermal stability of $p$-hydroxybenzoate hydroxylase. J. Biol. Chem. 282, 19969-19978.

Tajima, M., Urabe, I., Yutani, K., Okada, H., 1976. Role of calcium ions in the thermostability of thermolysin and Bacillus subtilis var. amylosacchariticus neutral protease. Eur. J. Biochem. 64, 243-247.

Takita, T., Aono, T., Sakurama, H., Itoh, T., Wada, T., Minoda, M., Yasukawa, K., Inouye, K., 2008. Effects of introducing negative charges into the molecular surface of thermolysin by site-directed mutagenesis on its activity and stability. Biochim. Biophys. Acta $1784,481-488$.

Tatsumi, C., Hashida, Y., Yasukawa, K., Inouye, K., 2007. Effects of site-directed mutagenesis of the surface residues $G \ln 128$ and Gln225 of thermolysin on its catalytic activity. J. Biochem. 141, 835-842.

Wallon, G., Lovett, S.T., Magyar, C., Swingor, A., Szilagyi, A., Zavodsky, P., Ringe, D., Petsko, G.A., 1997. Sequence and homology model of 3-isopropylmalate dehydrogenase from the psychrotrophic bacterium Vibrio sp. I5 suggest reasons for thermal instability. Protein Eng. 10, 665-672.

Yasukawa, K. Inouye, K., 2007. Improving the activity and stability of thermolysin by site-directed mutagenesis. Biochim. Biophys. Acta 1774, 1281-1288.

Yasukawa, K., Kusano, M., Inouye, K., 2007. A new method for the extracellular production of recombinant thermolysin by co-expressing the mature sequence and pro-sequence in Escherichia coli. Protein Eng. Des. Sel. 20, 375-383. 
Yutani, K., Ogasahara, K., Tsujita, T., Sugino, Y., 1987. Dependence of conformational stability on hydrophobicity of the amino acid residue in a series of variant proteins substituted at a unique position of tryptophan synthase $\alpha$ subunit. Proc. Natl. Acad. Sci. USA $84,4441-4444$.

Van den Burg, B., Eijsink, V.G., 2004. Thermolysin. In: Barrett, J.A., Rawlings, N.D., Woessner, J.F. (Eds.), Handbook of Proteolytic Enzymes, 2nd ed. Elsevier, Amsterdam, The Netherlands, Vol. 1, pp. 374-387. 


\section{Figure legends}

Fig. 1. Residues of thermolysin subject to mutation. The structure is based on Protein Data Bank number 8TLN (Holmes and Matthews, 1982; Hangauer et al., 1984). Peptide chain is displayed by a ribbon model. Residues subject to mutation are displayed by ball and stick. (A) The overall protein structure. (B) The active site. Five active-site regions, $\mathrm{N}, \alpha 1, \mathrm{C} 1, \alpha 2$, and $\mathrm{C} 2$ denote the N-terminal sheet (Asn112-Trp115), $\alpha$-helix 1 (Val139-Thr149), C-terminal loop 1 (Asp150-Gly162), $\alpha$-helix 2 (Ala163-Val176), and C-terminal loop 2 (Gln225-Ser234), respectively. (C) The N-terminal region. Distances from the $\mathrm{C}_{\alpha}$ atoms of the amino acid residues to the active-site zinc ion $(\AA)$ : Gly8, 30.5; Ser53, 25.1; Asn60, 32.4; Ser65, 26.8; Leu144, 9.2; Asp150, 11.7; Leu155, 11.8; and Ile168, 8.6.

Fig. 2. SDS-PAGE of wild-type (WT) thermolysin and its variants. Coomassie Brilliant Blue-stained 12.5\% SDS-polyacrylamide gels were shown. (A) The culture supernatants of the E. coli transformants with the expression plasmids for WT thermolysin and its variants bearing the activating mutations. The marker proteins (lanes 1 and 13), native thermolysin purified from B. thermoproteolyticus (lanes 2 and 12), the supernatants of $E$. coli cells transformed with pUC19 (lane 3), the expression plasmid for WT (lane 4), L144S (lane 5), D150E (lane 6), I168A (lane 7), L144S/D150E (lane 8), L144S/I168A (lane 9), D150E/I168A (lane 10), and L144S/D150E/I168A (lane 11). (B) The culture supernatants of the E. coli transformants with the expression plasmids for WT thermolysin and its variants bearing the stabilizing mutations. The marker proteins (lanes 1 and 17), native thermolysin 
purified from B. thermoproteolyticus (lanes 2 and 16), the supernatants of E. coli cells transformed with pUC19 (lane 3), the expression plasmid for WT (lane 4), S53D (lane 5), L155A (lane 6), G8C/N60C/S65P (lane 7), S53D/L155A (lane 8), $\mathrm{S} 53 \mathrm{D} / \mathrm{G} 8 \mathrm{C} / \mathrm{N} 60 \mathrm{C} / \mathrm{S} 65 \mathrm{P} \quad$ (lane 9), L155A/G8C/N60C/S65P (lane 10), S53D/L155A/G8C/N60C/S65P (lane 11), L144S/D150E/S53D (lane 12), L144S/D150E/L155A (lane 13), L144S/D150E/S53D/L155A (lane 14), and L144S/D150E/I168A/S53D/L155A/G8C/N60C/S65P (lane 15). (C) Purified proteins of WT thermolysin and its variants from the culture supernatants. The marker proteins (lanes 1 and 18), native thermolysin purified from B. thermoproteolyticus (lanes 2 and 17), WT (lane 3), L144S (lane 4), D150E (lane 5), I168A (lane 6), L144S/D150E (lane 7), D150E/I168A (lane 8), S53D (lane 9), L155A (lane 10), G8C/N60C/S65P (lane 11), S53D/L155A (lane 12), S53D/G8C/N60C/S65P (lane 13), L155A/G8C/N60C/S65P (lane 14), S53D/L155A/G8C/N60C/S65P (lane 15), and L144S/D150E/S53D (lane 16).

Fig. 3. Dependence on the substrate concentration of the initial reaction rate $\left(v_{0}\right)$ in the thermolysin-catalyzed hydrolysis of ZDFM. The reaction was carried out with the initial enzyme concentration $\left([\mathrm{E}]_{\mathrm{o}}\right)$ of $33-100 \mathrm{nM}$ at $25^{\circ} \mathrm{C} \cdot v_{\mathrm{o}} /[\mathrm{E}]_{\mathrm{o}}$ is plotted against the ZDFM concentration. Symbols for the enzymes: (A) WT, $\bigcirc$; L144S, $\square$; D150E, $\triangle$; I168A, $\diamond$; L144S/D150E, $\mathbf{\square}$; and D150E/I168A, $\mathbf{\Delta .}$ (B) WT, $\bigcirc$; S53D, $\square$; L155A, $\triangle ; \mathrm{G} 8 \mathrm{C} / \mathrm{N} 60 \mathrm{C} / \mathrm{S} 65 \mathrm{P}, \diamond ; \mathrm{S} 53 \mathrm{D} / \mathrm{L} 155 \mathrm{~A}, \quad$; S53D/G8C/N60C/S65P, $\mathbf{\square}$; L155A/G8C/N60C/S65P, $\quad \boldsymbol{\Delta} \quad ; \quad \mathrm{S} 53 \mathrm{D} / \mathrm{L} 155 \mathrm{~A} / \mathrm{G} 8 \mathrm{C} / \mathrm{N} 60 \mathrm{C} / \mathrm{S} 65 \mathrm{P}, \quad \boldsymbol{\nabla} \quad$ and L144S/D150E/S53D, $\boldsymbol{\nabla}$. Solid line represents the best fit of the Michaelis-Menten equation using the nonlinear least-squares methods. Error bars indicate SD values. 
Fig. 4. Thermal inactivation of thermolysins. Thermolysin $(1-2 \mu \mathrm{M})$ in $40 \mathrm{mM}$ HEPES-NaOH (pH 7.5) buffer containing $10 \mathrm{mM} \mathrm{CaCl}_{2}$ was incubated at $80^{\circ} \mathrm{C}$ for a specified time. The FAGLA-hydrolysis reaction was carried out with the initial concentrations of enzyme and FAGLA of $33-100 \mathrm{nM}$ and $400 \mu \mathrm{M}$, respectively, at $25^{\circ} \mathrm{C}$. The remaining activity $\left(k_{\mathrm{cat}} / K_{\mathrm{m}}\right)$ was expressed as the relative value to that of the intact enzyme and plotted against the incubation time. Symbols for the enzymes used in panels A and B are the same as those in Fig. 3. Solid line represents the best fit of the Michaelis-Menten equation using the nonlinear least-squares methods. Error bars indicate SD values.

Fig. 5. Comparison of the activity, the degree of $\mathrm{NaCl}$-induced activation, and stability of the thermolysin variants. (A) Comparison of the degree of $\mathrm{NaCl}$-induced activation at $4 \mathrm{M} \mathrm{NaCl}$ in the hydrolysis of FAGLA with the FAGLA-hydrolytic activity. (B) Comparison of the $k_{\mathrm{obs}}$ value with the FAGLA-hydrolytic activity. The values of FAGLA-hydrolytic activities at $\mathrm{pH} 7.5$ at $0 \mathrm{M} \mathrm{NaCl}$ and the degree of its $\mathrm{NaCl}$-induced activation at $4 \mathrm{M} \mathrm{NaCl}$ for WT and its variants are cited from Table 3. The $k_{\text {obs }}$ of the thermal inactivation at $80^{\circ} \mathrm{C}$ for WT and its variants are cited from Table 5. Symbols for the enzymes: WT, $\bigcirc$; L144S, $\square$; D150E, $\triangle$; I168A, $\diamond$;

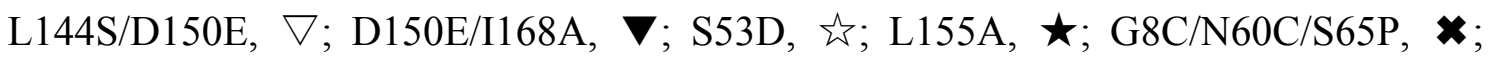
$\mathrm{S} 53 \mathrm{D} / \mathrm{L} 155 \mathrm{~A}, \quad \mathbf{+} ; \mathrm{S} 53 \mathrm{D} / \mathrm{G} 8 \mathrm{C} / \mathrm{N} 60 \mathrm{C} / \mathrm{S} 65 \mathrm{P}, \quad$ ○ L155A/G8C/N60C/S65P, 口 ; S53D/L155A/G8C/N60C/S65P, $\boldsymbol{\Delta}$; and L144S/D150E/S53D, $\bullet$. Solid line represents the best fit of the linear function using the linear least-squares methods. The regression 
coefficient, $r$, is: (A) -0.79 and (B) 0.51 . 
Table 1. Mutations which increase the activity or stability of thermolysin.

\begin{tabular}{|c|c|}
\hline Mutation & Site of the mutated residue \\
\hline \multicolumn{2}{|c|}{ (i) Activating mutations } \\
\hline Leu $144 \rightarrow$ Ser $^{\text {a }}$ & $\alpha$-helix 1 in the active site \\
\hline Asp $150 \rightarrow$ Glu $^{\text {b }}$ & C-terminal loop 1 in the active site \\
\hline Ile $168 \rightarrow$ Ala $^{\mathrm{b}}$ & $\alpha$-helix 2 in the active site \\
\hline \multicolumn{2}{|c|}{ (ii) Stabilizing mutations } \\
\hline Ser53 $\rightarrow$ Asp $^{c}$ & loop in the N-terminal domain \\
\hline Leu155 $\rightarrow$ Ala $^{d}$ & C-terminal loop 1 in the active site \\
\hline Gly $8 \rightarrow$ Cys/Asn60 $\rightarrow$ Cys/Ser65 $\rightarrow$ Pro ${ }^{e}$ & loop in the N-terminal domain \\
\hline
\end{tabular}

${ }^{a}$ Hanzawa and Kidokoro, 1999; Yasukawa and Inouye, 2007

${ }^{\mathrm{b}}$ Kusano et al., 2009

${ }^{c}$ Takita et al., 2008

d Matsumiya et al., 2004, 2005

${ }^{\mathrm{e}}$ Mansfeld et al., 1997; Yasukawa and Inouye, 2007 
Table 2. Casein-hydrolysis activity of the thermolysin variants at $25^{\circ} \mathrm{C}$

\begin{tabular}{|c|c|c|}
\hline Thermolysin & $\begin{array}{c}\text { Activity of the } \\
\text { culture supernatant } \\
\text { (units } / \mathrm{ml} \text { ) }\end{array}$ & $\begin{array}{c}\text { Specific activity of } \\
\text { purified enzyme } \\
\text { (units/mg) }\end{array}$ \\
\hline WT & $320 \pm 5$ & $10800 \pm 100$ \\
\hline
\end{tabular}

(i) Variants with the activating mutations
L144S
$26 \pm 12$
$(0.1)$
$3600 \pm 500$
D150E
$339 \pm 7$
(1.1) $\quad 10500 \pm 900$
I168A
$249 \pm 7$
$(0.8)$
$9600 \pm 800$
L144S/D150E
$25 \pm 1$
$(0.1)$
L144S/I168A
0
(0)
D150E/I168A
L144S/D150E/I168A
$196 \pm 4$
(0.6) $\quad 7500 \pm 1300$
0
(0)

(ii) Variants with the stabilizing mutations

$\begin{array}{lrccc}\text { S53D } & 338 \pm 4 & (1.1) & 11300 \pm 300 & (1.0) \\ \text { L155A } & 18 \pm 2 & (0.1) & 6700 \pm 0 & (0.6) \\ \text { G8C/N60C/S65P } & 316 \pm 2 & (1.0) & 10800 \pm 1200 & (1.0) \\ \text { S53D/L155A } & 15 \pm 1 & (0.1) & 10200 \pm 1500 & (0.9) \\ \text { S53D/G8C/N60C/S65P } & 398 \pm 4 & (1.2) & 11900 \pm 2000 & (1.1) \\ \text { L155A/G8C/N60C/S65P } & 19 \pm 2 & (0.1) & 8100 \pm 300 & (0.8) \\ \text { S53D/L155A/G8C/N60C/S65P } & 25 \pm 1 & (0.1) & 7900 \pm 1400 & (0.7)\end{array}$

(iii) Variants with the activating and stabilizing mutations

\begin{tabular}{lcll} 
L144S/D150E/S53D & $12 \pm 3$ & $(0.04)$ & $3600 \pm 200$ \\
L144S/D150E/L155A & 0 & $(0)$ \\
L144S/D150E/S53D/L155A & 0 & $(0)$ \\
L144S/D150E/I168A/S53D/L155A/G8C/N60C/S65P & 0 & $(0)$ \\
\hline
\end{tabular}

The average of triplicate determination with SD values is shown. Numbers in parentheses indicate the values relative to wild-type thermolysin. 
Table 3. FAGLA-hydrolysis activity of the thermolysin variants in the hydrolysis of FAGLA at 0 and $4 \mathrm{M} \mathrm{NaCl}$ at $25^{\circ} \mathrm{C}$.

\begin{tabular}{llll}
\hline \multirow{2}{*}{ Thermolysin } & \multicolumn{2}{c}{$k_{\mathrm{cat}} / K_{\mathrm{m}} \times 10^{-4}\left(\mathrm{M}^{-1} \mathrm{~s}^{-1}\right)$} & \multirow{2}{*}{ (B/A) } \\
\cline { 2 - 3 } & $0 \mathrm{M} \mathrm{NaCl}(\mathrm{A})$ & $4 \mathrm{M} \mathrm{NaCl}(\mathrm{B})$ & \\
\hline WT & $2.9 \pm 0.2(1.0)$ & $38 \pm 1(1.0)$ & $13(1.0)$
\end{tabular}

(i) Variants with the activating mutations

$\begin{array}{lcll}\text { L144S } & 18.2 \pm 1.0(6.3) & 66 \pm 13(1.7) & 4(0.3) \\ \text { D150E } & 7.9 \pm 0.2(2.7) & 40 \pm 1(1.1) & 5(0.4) \\ \text { I168A } & 6.2 \pm 0.2(2.1) & 30 \pm 2(0.8) & 5(0.4) \\ \text { L144S/D150E } & 20.4 \pm 0.3(7.0) & 59 \pm 3(1.6) & 3(0.2) \\ \text { D150E/I168A } & 14.1 \pm 0.3(4.9) & 60 \pm 1(1.6) & 4(0.3)\end{array}$

(ii) Variants with the stabilizing mutations

S53D

L155A

G8C/N60C/S65P

$\mathrm{S} 53 \mathrm{D} / \mathrm{L} 155 \mathrm{~A}$

$\mathrm{S} 53 \mathrm{D} / \mathrm{G} 8 \mathrm{C} / \mathrm{N} 60 \mathrm{C} / \mathrm{S} 65 \mathrm{P}$

L155A/G8C/N60C/S65P

S53D/L155A/G8C/N60C/S65P

$$
\begin{array}{llr}
3.2 \pm 0.1(1.1) & 39 \pm 0(1.0) & 12(0.9) \\
2.6 \pm 0.0(0.9) & 21 \pm 2(0.6) & 8(0.6) \\
2.9 \pm 0.0(1.0) & 35 \pm 1(0.9) & 12(0.9) \\
3.3 \pm 0.1(1.1) & 32 \pm 2(0.8) & 10(0.8) \\
3.1 \pm 0.3(1.1) & 40 \pm 1(1.1) & 13(1.0) \\
3.4 \pm 0.0(1.2) & 43 \pm 2(1.1) & 13(1.0) \\
2.3 \pm 0.1(0.8) & 33 \pm 1(0.9) & 14(1.1)
\end{array}
$$

(iii) Variants with the activating and stabilizing mutations

$$
\text { L144S/D150E/S53D }
$$$$
24.9 \pm 0.2(8.6) \quad 117 \pm 0(3.1)
$$

The reaction was carried out in $40 \mathrm{mM}$ HEPES-NaOH buffer at $\mathrm{pH} 7.5$ containing 10 $\mathrm{mM} \mathrm{CaCl} 2$, at $25^{\circ} \mathrm{C}$. The average of triplicate determination with SD value is shown. Numbers in parentheses indicate values relative to wild-type thermolysin. 
Table 4. Kinetic parameters of the thermolysin variants in the hydrolysis of ZDFM at $25^{\circ} \mathrm{C}$

\begin{tabular}{lccc}
\hline Thermolysin & $K_{\mathrm{m}}(\mathrm{mM})$ & $k_{\mathrm{cat}}\left(\mathrm{s}^{-1}\right)$ & $k_{\mathrm{cat}} / K_{\mathrm{m}}\left(\mathrm{mM}^{-1} \mathrm{~s}^{-1}\right)$ \\
\hline WT & $0.63 \pm 0.05(1.0)$ & $5.9 \pm 0.2(1.0)$ & $9.4 \pm 0.4(1.0)$
\end{tabular}

(i) Variants with the activating mutations
L144S
$0.19 \pm 0.02(0.3)$
$9.4 \pm 0.3(1.6)$
$49.7 \pm 4.6(5.3)$
D150E
$0.50 \pm 0.05(0.8)$
$16.5 \pm 0.7(2.8)$
$33.1 \pm 2.1(3.5)$
I168A
$0.46 \pm 0.03(0.7)$
$7.7 \pm 0.2(1.3)$
$16.8 \pm 0.7(1.8)$
L144S/D150E
$0.17 \pm 0.03(0.3)$
$17.0 \pm 0.8(2.9)$
$99.0 \pm 10.8(10.5)$
D150E/I168A
$0.18 \pm 0.02(0.3)$
$15.5 \pm 0.6(2.6)$
$83.8 \pm 7.0(8.9)$

(ii) Variants with the stabilizing mutations

$\begin{array}{lllr}\text { S53D } & 0.77 \pm 0.06(1.2) & 6.9 \pm 0.3(1.2) & 9.0 \pm 0.4(1.0) \\ \text { L155A } & 1.29 \pm 0.21(2.0) & 8.7 \pm 0.8(1.5) & 6.7 \pm 0.5(0.7) \\ \text { G8C/N60C/S65P } & 0.54 \pm 0.04(0.9) & 5.4 \pm 0.2(0.9) & 10.0 \pm 0.5(1.1) \\ \text { S53D/L155A } & 0.69 \pm 0.13(1.1) & 6.4 \pm 0.5(1.1) & 9.2 \pm 0.9(1.0) \\ \text { S53D/G8C/N60C/S65P } & 0.94 \pm 0.09(1.5) & 7.4 \pm 0.4(1.3) & 7.9 \pm 0.4(0.8) \\ \text { L155A/G8C/N60C/S65P } & 0.83 \pm 0.13(1.3) & 6.3 \pm 0.5(1.1) & 7.5 \pm 0.6(0.8) \\ \text { S53D/L155A/G8C/N60C/S65P } & 0.55 \pm 0.06(0.9) & 3.3 \pm 0.2(0.6) & 6.0 \pm 0.4(0.6)\end{array}$

(iii) Variants with the activating and stabilizing mutations

The average of triplicate determination with SD values is shown. Numbers in parentheses indicate the values relative to wild-type thermolysin. 
Table 5. The observed first-order rate constant for the thermal inactivation at $80^{\circ} \mathrm{C}$ of the thermolysin variants

\begin{tabular}{ll}
\hline Thermolysin & $k_{\mathrm{obs}}{ }^{\mathrm{a}} \times 10^{4}\left(\mathrm{~s}^{-1}\right)$ \\
\hline WT & $8.4 \pm 0.1(1.0)$
\end{tabular}

(i) Variants with the activating mutations
L144S
$8.2 \pm 0.6(1.0)$
$\mathrm{D} 150 \mathrm{E}$
$7.8 \pm 0.2(0.9)$
I168A
$9.4 \pm 0.2(1.1)$
L144S/D150E
$7.7 \pm 0.5(0.9)$
D150E/I168A
$14.7 \pm 0.5(1.8)$

(ii) Variants with the stabilizing mutations

S53D

$$
1.9 \pm 0.1(0.2)
$$

L155A

$2.1 \pm 0.1(0.3)$

G8C/N60C/S65P

$2.1 \pm 0.1(0.3)$

S53D/L155A

$0.9 \pm 0.1(0.1)$

$\mathrm{S} 53 \mathrm{D} / \mathrm{G} 8 \mathrm{C} / \mathrm{N} 60 \mathrm{C} / \mathrm{S} 65 \mathrm{P}$

$2.4 \pm 0.2(0.3)$

L155A/G8C/N60C/S65P

$1.3 \pm 0.1(0.2)$

S53D/L155A/G8C/N60C/S65P

$1.2 \pm 0.0(0.1)$

(iii) Variants with the activating and stabilizing mutations L144S/D150E/S53D $5.1 \pm 0.3(0.6)$

${ }^{\mathrm{a}} k_{\text {obs }}$ is the observed first-order rate constant for the thermal inactivation at $80^{\circ} \mathrm{C}$. The average of triplicate determination with SD value is shown. Numbers in parentheses indicate values relative to wild-type thermolysin. 
A

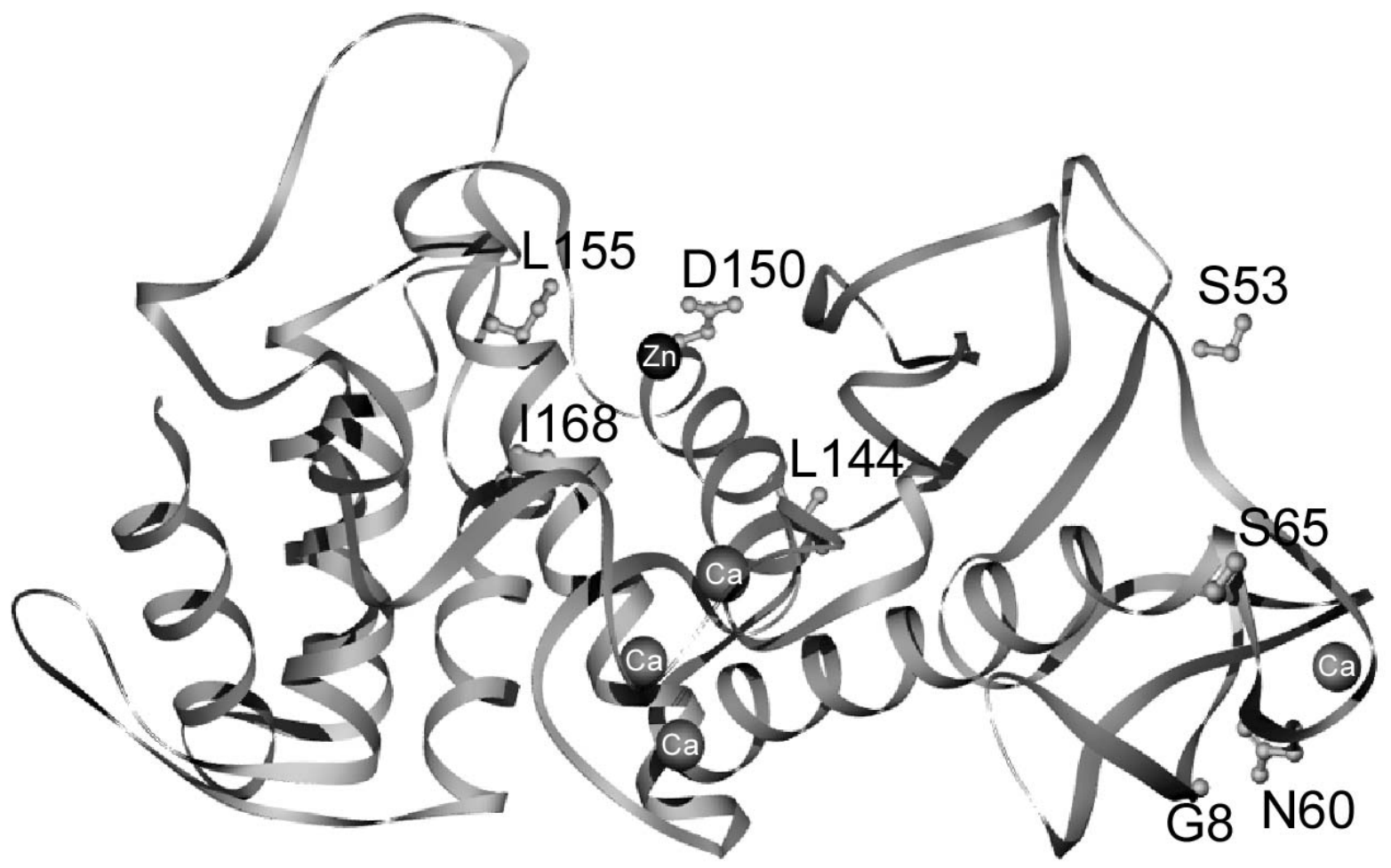

Fig. 1 
B

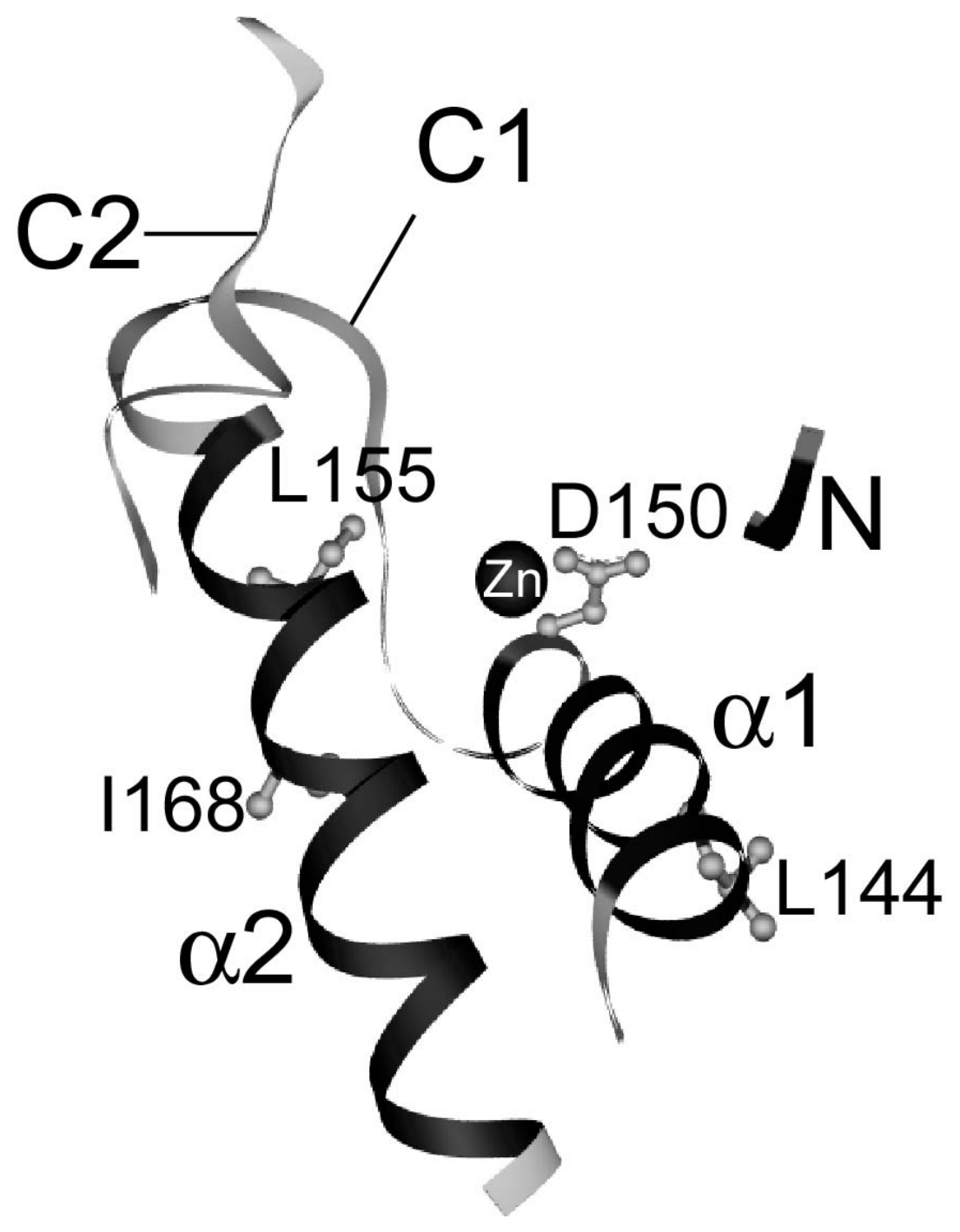

Fig. 1 
C

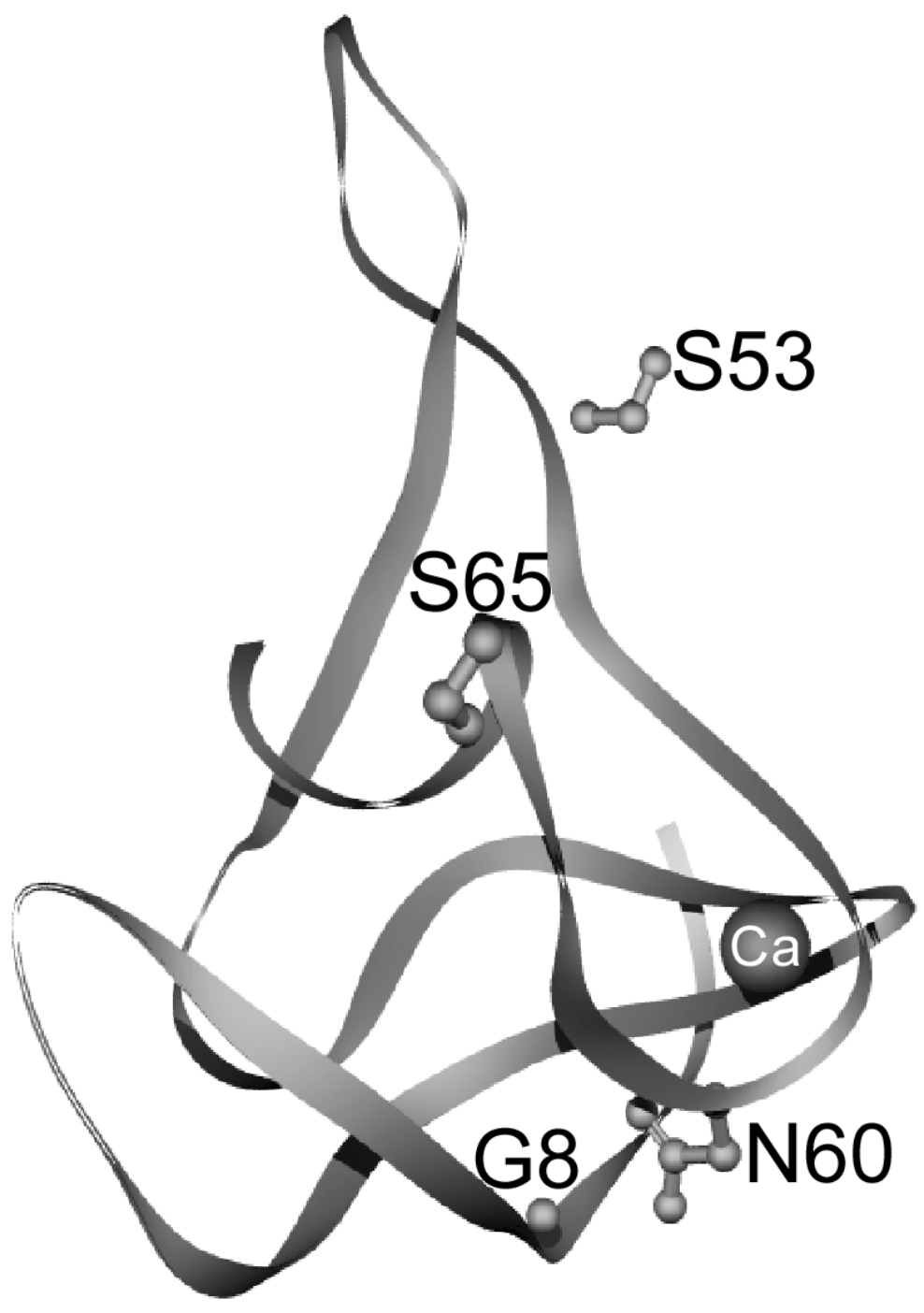

Fig. 1 
A

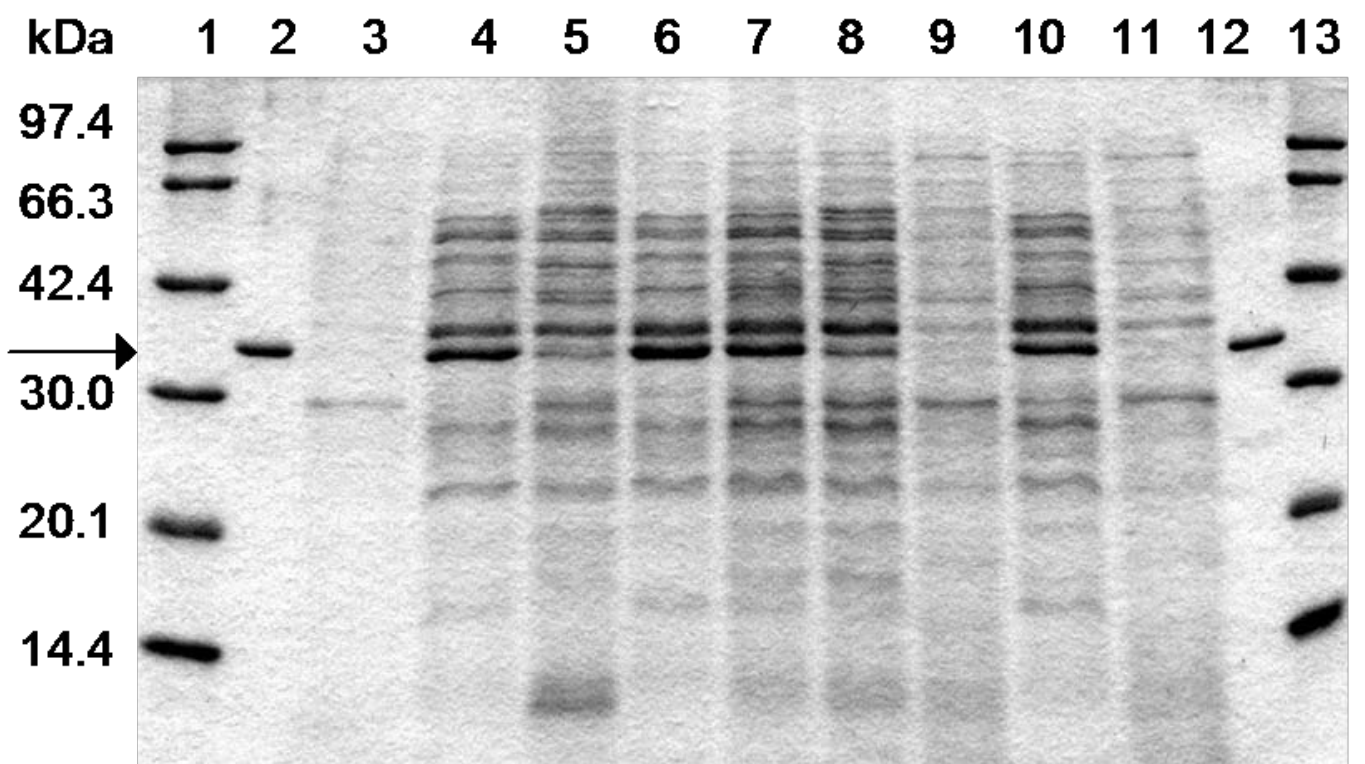

Fig. 2 
B

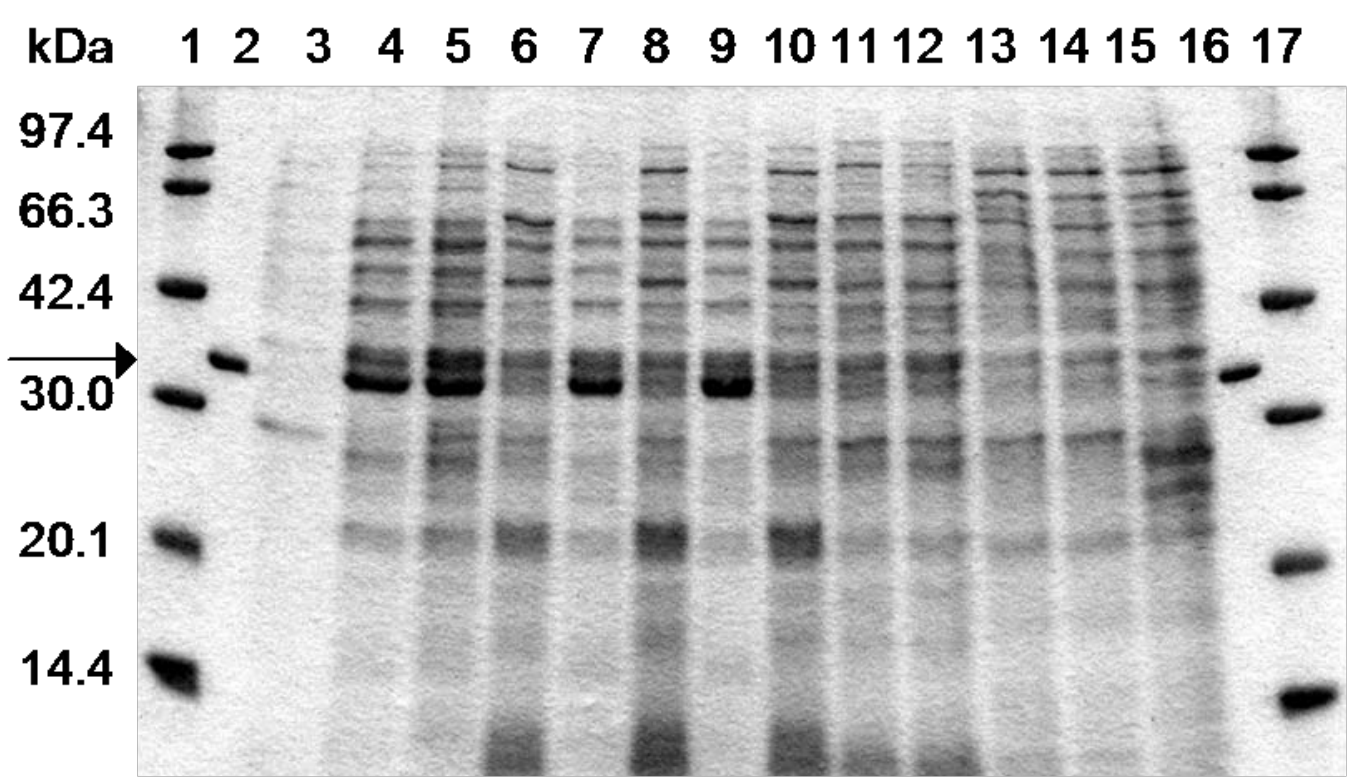

Fig. 2 
C

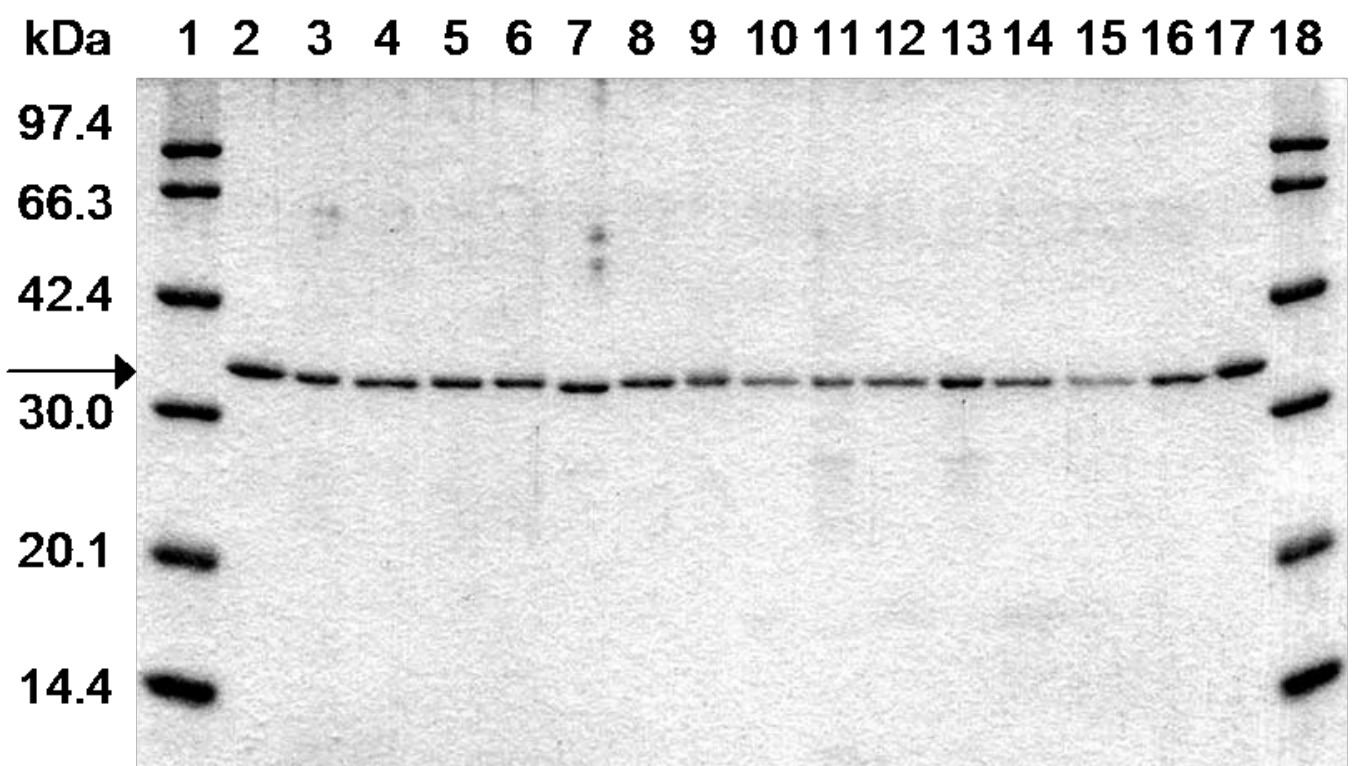

Fig. 2 
A

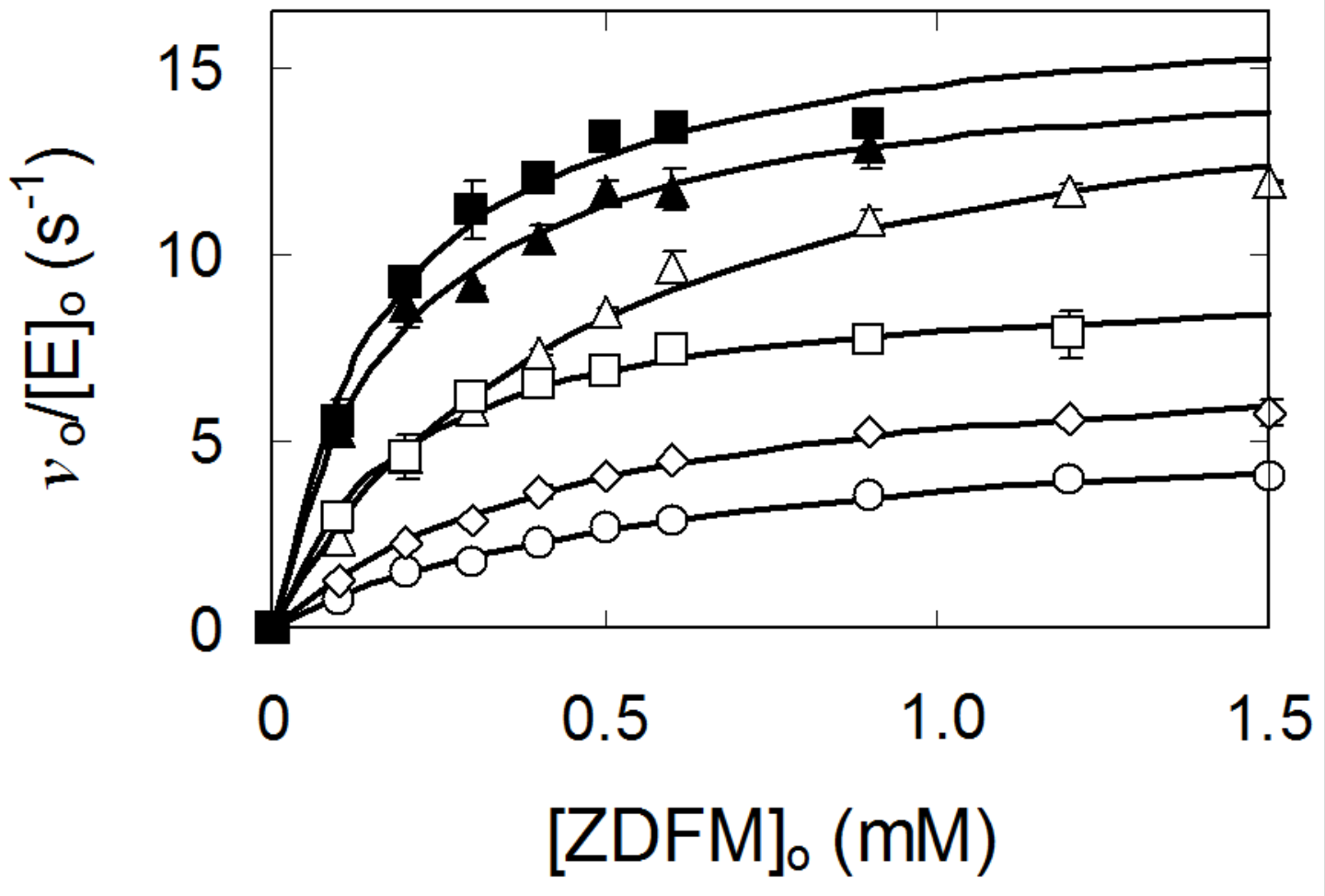

Fig. 3 
B

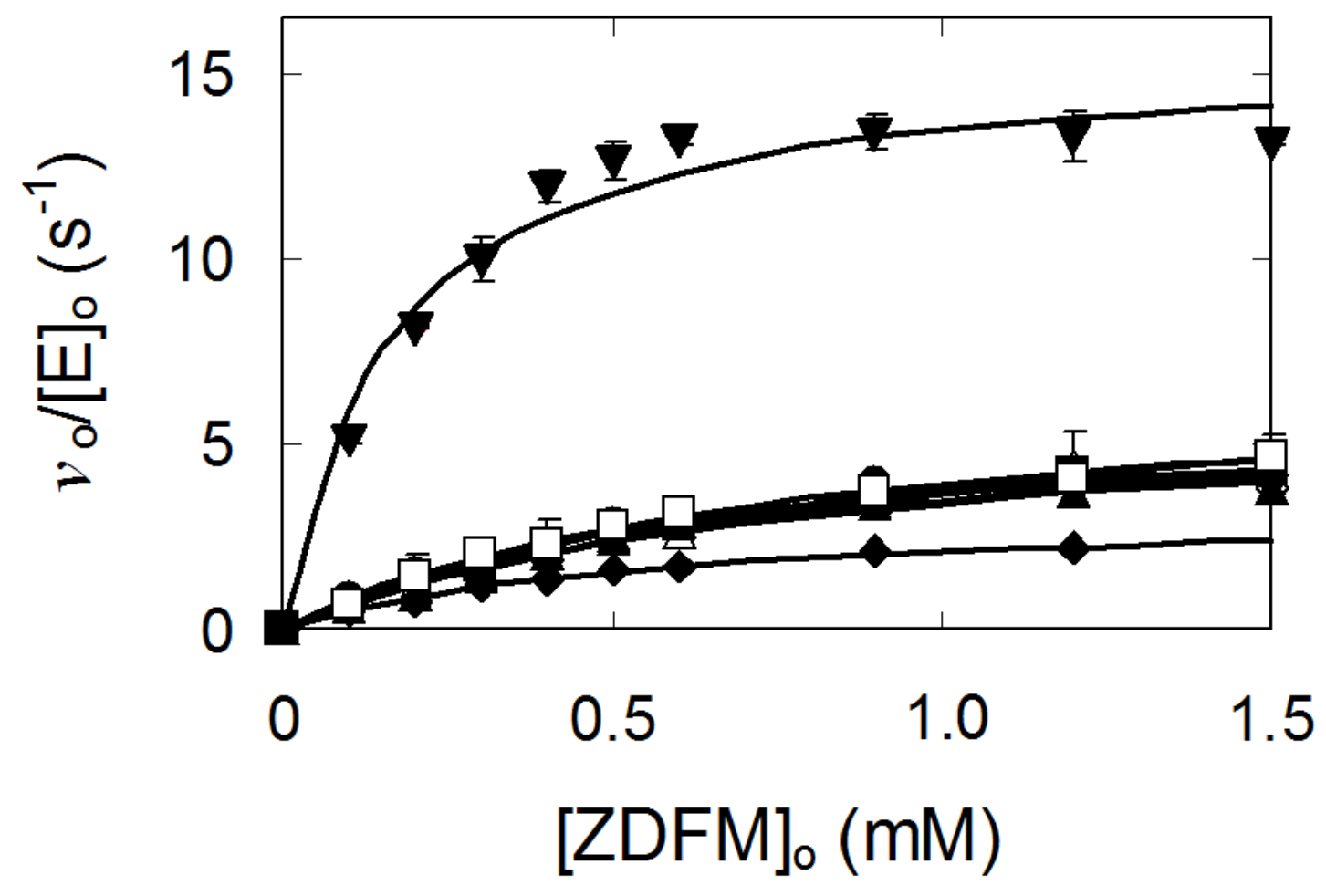

Fig. 3 
A

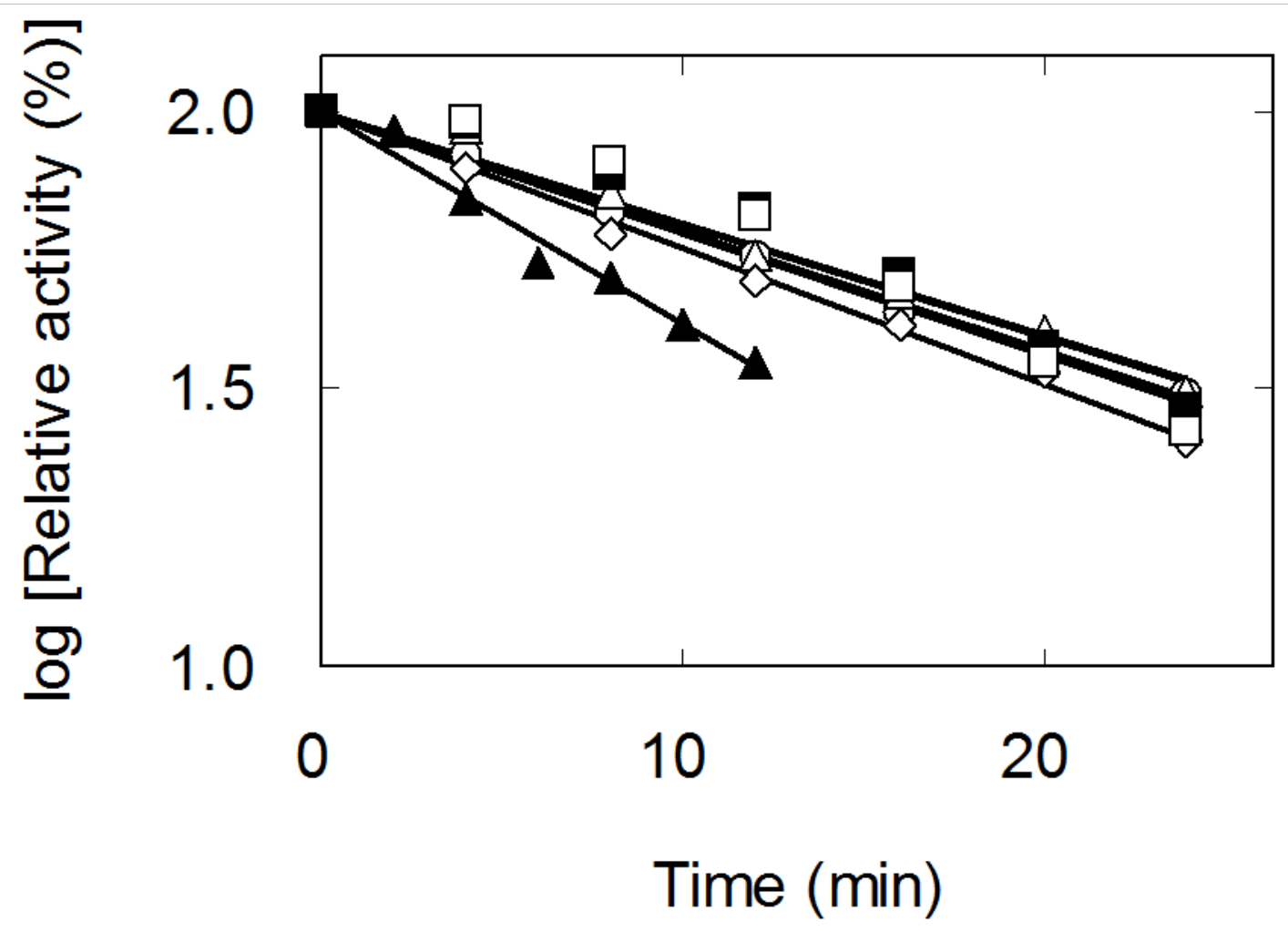

Fig. 4 
B

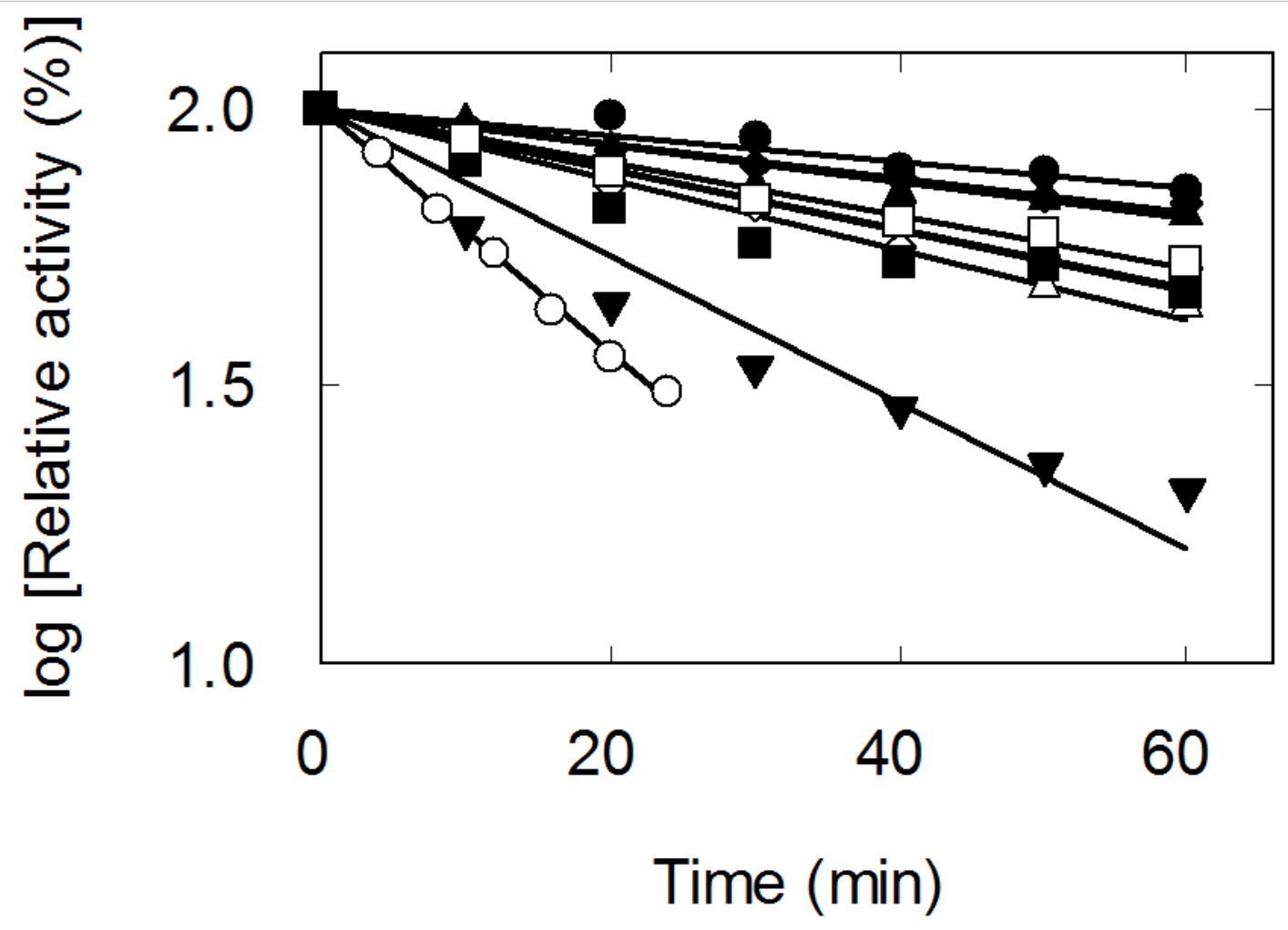

Fig. 4 
A

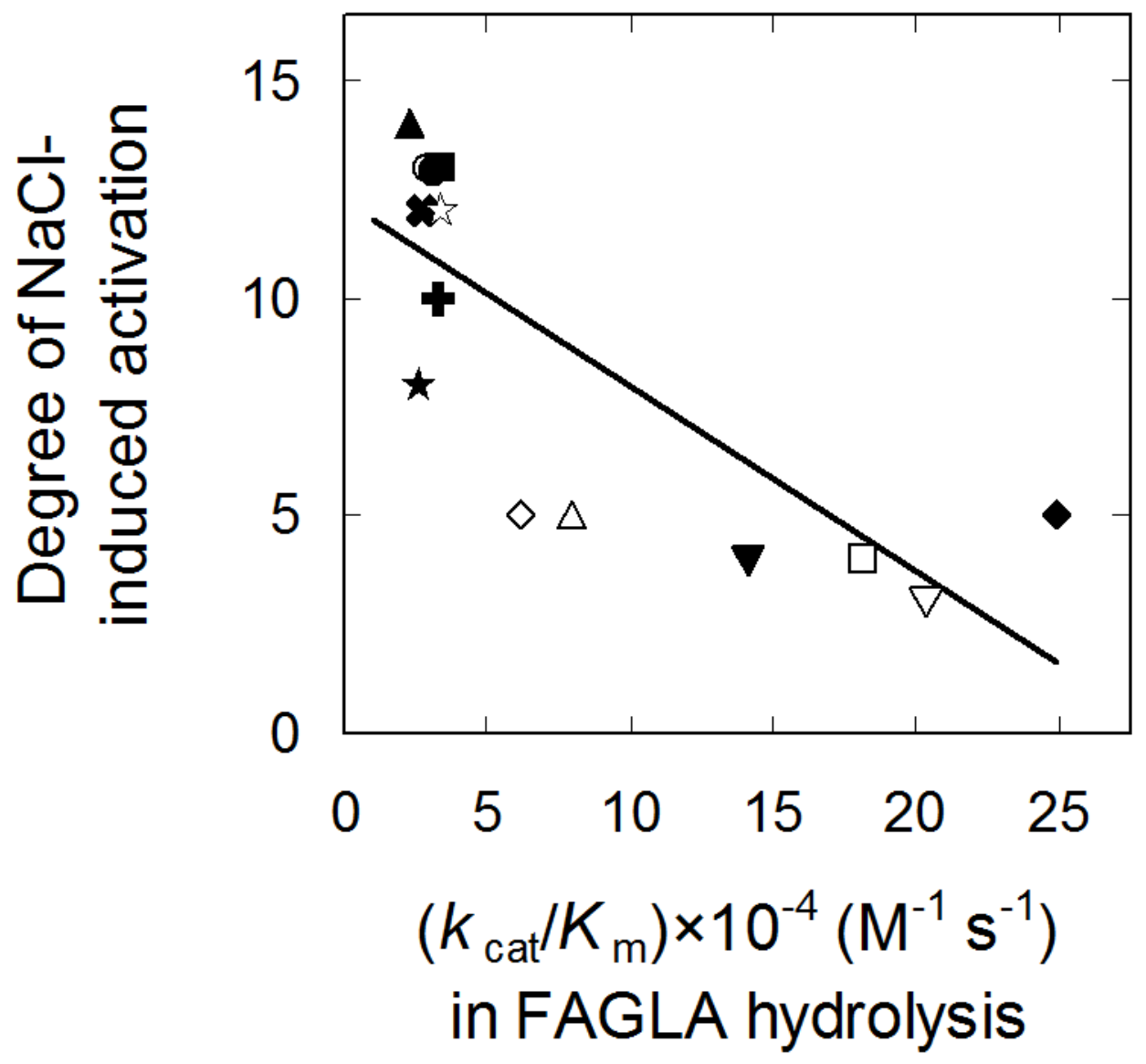

Fig. 5 
B

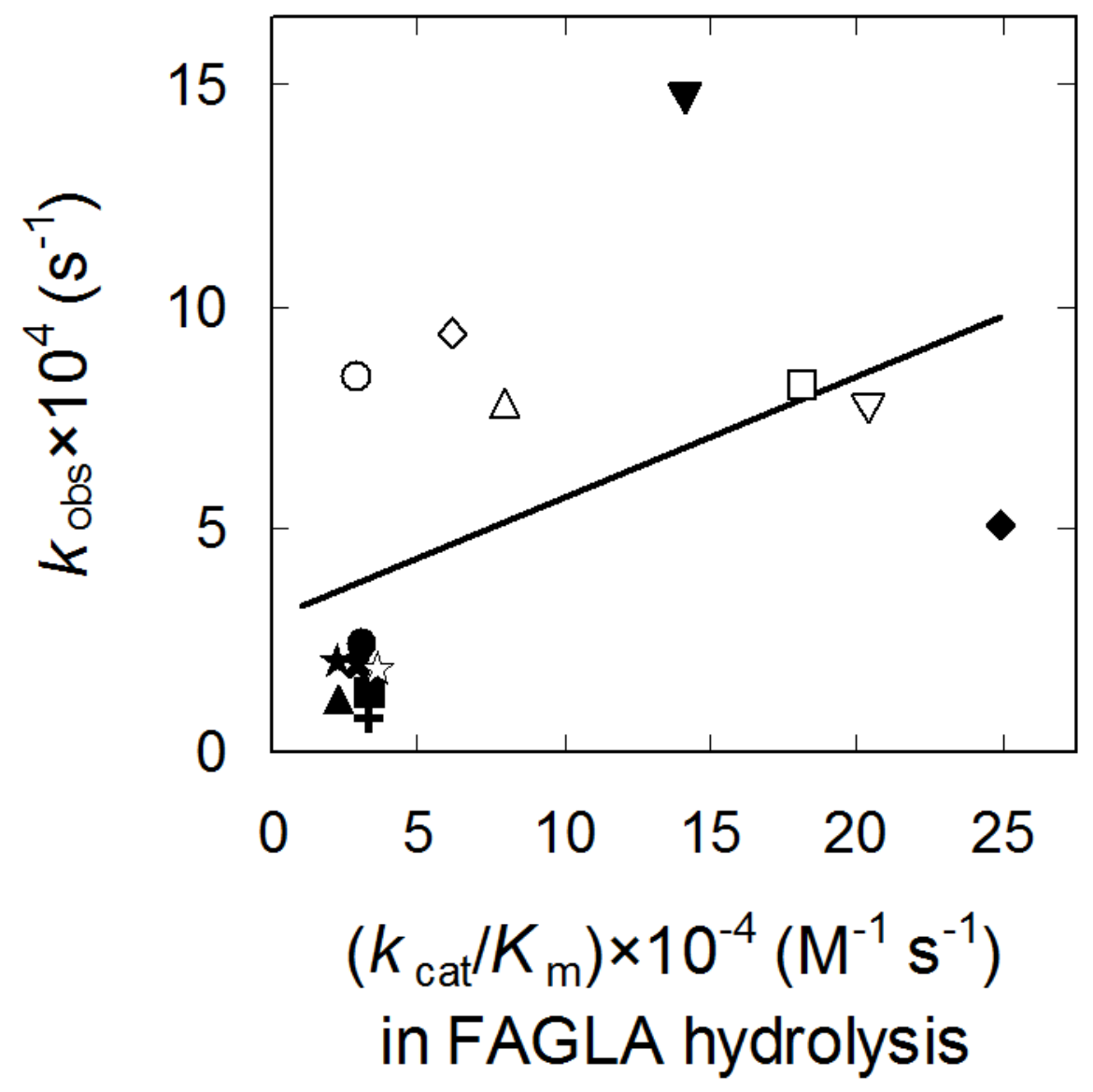

Fig. 5 